\title{
Mound Facility Activities in Chemical and Physical Research: July-December 1979
}

Issued: June 18, 1980

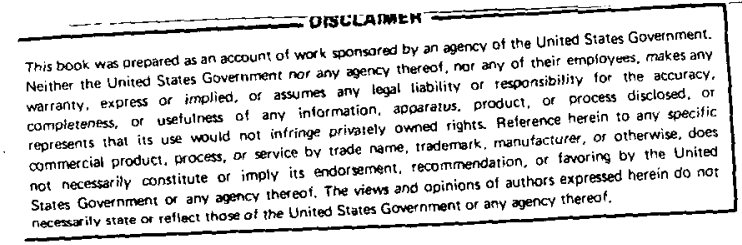

\section{MOUND FACILITY}

Miamisburg, Ohio 45342

operated by

\section{MONSANTO RESEARCH CORPORATION}

a subsidiary of Monsanto Company

for the

\section{U. S. DEPARTMENT OF ENERGY}

Contract NO. DE-ACOA-75-DPOOOS3 


\section{DISCLAIMER}

This report was prepared as an account of work sponsored by an agency of the United States Government. Neither the United States Government nor any agency Thereof, nor any of their employees, makes any warranty, express or implied, or assumes any legal liability or responsibility for the accuracy, completeness, or usefulness of any information, apparatus, product, or process disclosed, or represents that its use would not infringe privately owned rights. Reference herein to any specific commercial product, process, or service by trade name, trademark, manufacturer, or otherwise does not necessarily constitute or imply its endorsement, recommendation, or favoring by the United States Government or any agency thereof. The views and opinions of authors expressed herein do not necessarily state or reflect those of the United States Government or any agency thereof. 


\section{DISCLAIMER}

Portions of this document may be illegible in electronic image products. Images are produced from the best available original document. 


\section{Foreword}

This report is issued semiannually by Mound Facility. Under the sponsorship of the DOE Division of Basic Energy Sciences, Mound Facility is responsible for producing materials for use in the physical sciences to further the progress of science and technology in the public interest. Additional research activities of related interest under the sponsorship of the Division of Military Application are also reported here.

This report is submitted by W. T. Cave, Director of Nuclear Operations, and R. E. Vallee, Manager of Technology Applications and Development, from contributions prepared by W. M. Rutherford, Science Fellow (Thermal Diffusioń); W. L. Taylor, Science Fellow (Gas Dynamics and Cryogenics); G. L. Silver, Science Fellow (Separation Chemistry); I. J. Wittenberg, Leader, Metal Hydride Research; and from members of the Isotope Separation Section: W. R. Wilkes, Isotope Separation Manager; E. D. Michaels, Leader, Isotope Separation Engineering; W. J. Roos, Leader, Stable Isotopes Inventory; B. E. Jepson, Senior Research Specialist, Metal Isotope Separation Research and Development; and R. E. Eppley, Leader, Uranium Isotope Chemistry and Radioisotope Inventory.

These reports are not intended to constitute publication in any sense of the word. Final results will either be submitted for publication in regular professional journals or be published in the form of MLM topical reports.

Previous reports in this series are:

MLM-2168

MLM-2198

MLM-2241

MLM-2296

MLM-2354
MLM-2414

MLM-2450

MLM-2506

MLM-2555

MLM-2590

MLM-2654 


\section{Contents}

\section{Isotope separation}

Production of 1.3 STP liters of $95 \%$ argon-38 was completed. Production modifications will permit processing of this relatively difficult-to-separate isotope to a high enrichment on a more frequent basis. Operating changes to the 13-column intermediate enrichment system have increased production by about 508 .

Approximately $520 \mathrm{~g}$ of $90+8$ carbon-13 as barium carbonate was produced by conversion from enriched carbon dioxide. In addition, $200 \mathrm{~g}$ of 998 and $130 \mathrm{~g}$ of 908 elemental carbon-13 were produced from enriched carbon monoxide.

HEL IUM

During this 6-month period approximately 5100 STP liters of 99.98 helium-3 was produced; also, the product loading system was upgraded to facilitate handling of high-pressure orders.

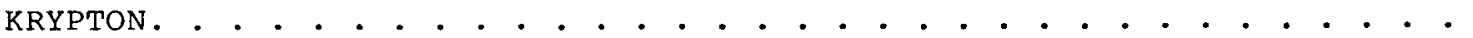

Production of 708 krypton-82 continued with an output of approximately 12.5 STP liters; 10.0 STP liters of 908 krypton-84 was processed as well as approximately 3.0 STP liters of 508 krypton-78. Production of 908 krypton -78 is expected to begin soon. Preparations are being made for enrichment of a new batch of neon21 to $>908$. Collection of enriched neon-20 and neon-22 by-products will proceed concurrent with the neon-21 enrichment. Enrichment of neon-20 which is slightly below product specification is continuing.

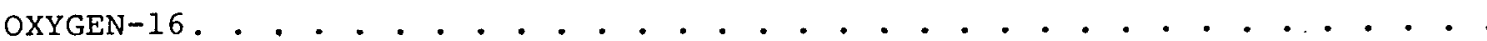
8 The new oxygen-16 electrolysis system was put into operation. Most of the initial problems associated with the start-up of the system have been solved. Approximately $11 \mathrm{~kg}$ of oxygen-l6 has been produced.

OXYGEN-17/18 . . . . . . . . . . . . . . . . . . . . . . . . . . During this period $120 \mathrm{~g}$ of 508 oxygen-17 and $394 \mathrm{~g}$ of 958 oxygen18 gas were produced. 
XENON

During this period 0.875 STP liter $20 \%$ xenon-124, 0.720 STP liter

$40 \%$ xenon-124, and 8.75 STP liters $80 \%$ xenon-136 were separated.

\section{Low temperature research}

HYDROGEN INTERMOLECULAR POTENTIAL FUNCTIONS. . . . . . . . . . . . . . . .

A study of the intermolecular potential functions for spherically symmetric para $\mathrm{H}_{2}$ has shown that the second virial data, the differential scattering data, and the bound state energies determined from spectroscopic data cannot all be described by any one of the published potential functions. We are therefore modifying a HartreeFock Dispersion type potential in an attempt to describe all the data.

A low temperature, condensed gas calorimeter has been constructed to be used in conjunction with vapor pressure measurements to determine latent heats at absolute zero in the study of intermolecular potential functions.

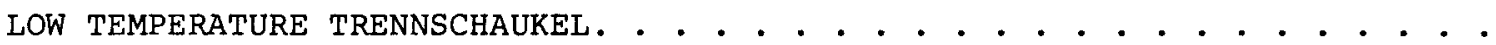

Sensors and associated electronics and hardware have been assembled for the construction of an accurate thermal conductivity gas analyzer. Sufficient temperature control has been achieved and standard gas mixtures have been obtained for calibration of the instrument. When the technique has been demonstrated on the bench, a low temperature trennschaukel will be instrumented for in situ determinations of the change in concentration of a gas mixture during thermal diffusion experiments. Systems to be studied are $\mathrm{He}-\mathrm{Ne}$ and ${ }^{3} \mathrm{He}-{ }^{4} \mathrm{He}$ from approximately 25-250 $\mathrm{K}$. The bench demonstrator model will remain intact for use in analyzing gas mixtures from other experiments.

\section{Separation chemistry}

THORIUM-229 . . . . . . . . . . . . . . . . . . . . . . . . . . . .

A total of $10.9 \mathrm{mg}$ of thorium-229 was separated from previously extracted and aged $\mathrm{U}_{3} \mathrm{O}_{8}$ and shipped to Isotope Sales at ORNL in FY-1979. The thorium-229 production facility has been placed on standby for FY-1980.

PROTACTINIUM-231 AND THORIUM-230 . . . . . . . . . . . . . . . . . . . . . The FY-1979 product comprised two shipments of thorium-230, totaling $56,900 \mathrm{mg}$, and one shipment of $132 \mathrm{mg}$ of protactinium-231. 


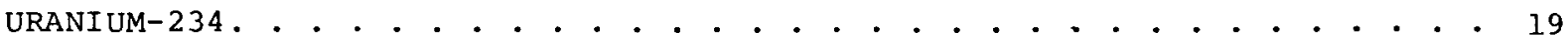

Separation and purification of two uranium-234 products were com-

pleted. Product A20 contained $8.884 \mathrm{~g}$ of uranium-234 at an isotopic purity of 99.8558 with $2.3 \mathrm{ppm}$ plutonium-238, and product A21 contained $3.473 \mathrm{~g}$ of uranium-234 at an isotopic purity of 99.6348 with $3.8 \mathrm{ppm}$ plutonium-238. All of product A20 and $1.116 \mathrm{~g}$ of product A21 were shipped to Isotope sales at ORNL.

\section{Separation research}

LIQUID THERMAL DIFFUSION . . . . . . . . . . . . . . . . . . . 21 Additional experiments were conducted with a new liquid thermal diffusion column designed specifically for research. Improved methods were developed for obtaining and reducing separation data as a function of time, and these methods were applied to isotopic separation experiments involving chlorobenzene, l-chloropropane, ethyl bromide and carbon disulfide. column parameters were obtained as functions of hot-to-cold wall spacing in the range from $178 \mu \mathrm{m}$ to $305 \mu \mathrm{m}$. Good agreement with theory was found at spacings equal to or greater than $200 \mathrm{~m}$. Some restriction to thermogravitational circulation was noted at $178 \mu \mathrm{m}$.

CALCIUM ISOTOPE SEPARATION . . . . . . . . . . . . . . . . . 28 Additional experiments were completed on calcium isotope separation by liquid phase thermal diffusion. Uniform solute concentrations were established by controlled solvent injection; however, significant separation of isotopes was found in only two out of eight samples. The separation was equivalent to a 5.8 shift in the abundance of calcium-48. Apparently the particular conditions chosen for the experiments led to unstable conditions and remixing of the column contents. A short column was constructed to evaluate isotope separation without solvent injection. Separations amounting to a $5 \%$ shift in calcium-48 abundance were observed.

$\mathrm{CaCl}_{2}$ solutions were found to be compatible with titanium at $180^{\circ} \mathrm{C}$, and $\mathrm{Ca}(\mathrm{SCN})_{2}$ solutions were found to be too unstable for use in a process.

MOLECULAR BEAM SCATTERING. . . . . . . . . . . . . . . . . . . . . . 34 The helium-argon total scattering cross section experiments have been successfully concluded. The neon-argon experimental cross sections were corrected for apparatus resolution and compared with theoretical values; results of the current data analysis are presented; further analyses are in progress. The rotatable, triplypumped detector housing has been successfully leak tested and is ready for istallation. 
MUTUAL DIFFUSION • • • • • • • • • • • • • • • • • • • • • • • • • • • • • • • • •

The study of diffusion coefficients, $D_{12}$, of krypton-noble gas systems has been completed over the presently attainable temperature range. Attention has since shifted to the systems helium-neon, argon, xenon, and argon-xenon. $D_{12}$ values have been determined at seven different temperatures for argon-xenon mixtures, covering a temperature range of 344-1106 K; five values of $\mathrm{D}_{12}$ have been measured for helium-xenon from 351-1217 K. As part of this study and also at the request of Prof. R. A. Aziz of the University of Waterloo, we have made a very careful study of the diffusion coefficient of heliumargon at approximately $1300 \mathrm{~K}$. The result of these high temperature experiments, plus some indirect information (interpolations and extrapolations) found in the literature, is the conclusion that the high temperature $D_{12}$ data of Hogervorst [W. Hogervorst, Physica, 51,59 (1971)] for helium-argon are too low by as much as $10 \%$ at $1400 \mathrm{~K}$.

LITHIUM CHEMICAL EXCHANGE WITH CRYPTANDS . . . . . . . . . . . . . . . . .

The water of hydration present in organic phase lithium complexes of (221) and (211) cryptands was determined by Karl Fischer titrations. For the 1ithium trifluoroacetate (LiTFA)-(221) cryptand chemical exchange system, the water concentration in the organic phase in excess of blanks corresponded closely to the lithium concentration, indicating that a lithium ion retains one molecule of hydration water when exchanging from the aquo to the organic phase (221) complex. In the LiTFA-(211) exchange system no water in excess of that in the blank was found; thus, the (211) complex excludes hydration water. The kinetics of the heterogeneous exchange rate for the LiTFA-(211) system was investigated and found to be slow relative to prior systems studied.

\section{Calculations in plutonium chemistry}

SHORT ALGORITHMS FOR PLUTONIUM CHEMISTRY . . . . . . . . . . . . . . . . .

Two- and three-variable optimization algorithms suitable for solving problems in plutonium chemistry by the method of proportional equations are presented. The methods may be used with programmable pocket calculators.

PROGRAM FOR PLUTONIUM VALENCES IN ENVIRONMENTAL WATER. . . . . . . . . .

A program is presented with computes the distribution of plutonium oxidation states, together with the absolute molar solubility of the plutonium in equilibrium with hydrous plutonium(IV) oxide. The program is suitable for programmable pocket calculators. 


\section{Isotope separation}

\section{Argon}

T. F. Walburg

Production of 1.3 STP liters of 95\% argon38 was completed. This rare middle isotope ( 0.0638 natural abundance) poses one of the more difficult separations for a thermal diffusion cascade separation. Now that additional argon-38 is available in sufficient quantity to establish the profile for a second, six-column enrichment cascade, it should be possible to produce this material on a more frequent basis. Also the 13-column cascade which produces intermediate enrichment feed ( $\sim 7$ to $10 \%$ argon-38) for the six-column system has benefited significantly from operating modifications. The modifications have currently resulted in a $50 \%$ increase in production rate. Production of $99.5 \%$ argon-36 continued with about 9.0 STP Iiters taken off the system.

\section{Carbon}

T. F. Walburg and G. E. Stuber

Approximately $280 \mathrm{~g}$ of 908 carbon-13 and $240 \mathrm{~g}$ of $98 \%$ carbon-13 as barium carbonate were produced by conversion from enriched carbon dioxide during the second half of the year. The new agitator for the large-scale barium carbonate reactor has arrived, and the larger conversion system should be in operation soon.

The reduction of enriched carbon monoxide produced $200 \mathrm{~g}$ of 998 and $130 \mathrm{~g}$ of $90 \%$ elemental carbon-13. The microprocessor used to control the elemental carbon conversion system has been disconnected to allow some hardware modifications and the installation of new operating software. Mechanical control devices have been installed to allow continued operation of the conversion system until the microprocessor modifications have been completed.

\section{Helium}

T. F. Walburg

Approximately 5100 STP liters of $99.9 \%$ helium-3 was produced during this period. The helium product loading system was upgraded with the installation of a highpressure compressor to facilitate loading customer orders up to 2000 psi.

\section{Krypton}

T. F. Walburg

Production of 708 krypton-82 was emphasized, with approximately 12.5 STP liters processed on the 10-column cascade. A second thermal diffusion cascade was brought into use to prepare enriched feed for the 10column system. This 19-column system may soon be processing product-grade material from natural abundance feed. This would be the first time this separation has been accomplished in a single cascade.

Another 19-column thermal diffusion cascade was used to prepare enriched krypton78 with approximately 3.0 STP liters of 508 material produced during this period. The system is currently being switched over for production of $90 \%$ krypton- 78 .

During this period approximately $10 \mathrm{STP}$ liters of $90 \%$ krypton-84 was also processed. 


\section{Neon}

W. J. ROOS

During this period, filling of a single large order for neon-21 required the entire inventory of that isotope. Preparations are currently being made to enrich a new batch of neon-21 to $>90 \%$. A sixcolumn thermal diffusion system is available for this purpose; it will be put into operation following necessary modifications and leak checking. Production of enriched material is expected to begin within 3-6 months. Collection of enriched neon-20 and neon-22 as by-products will be resumed.

Enrichment of neon-20 which is slightly below product specification (99.95\% neon20 ) is continuing in a four-column thermal diffusion system.

\section{Oxygen-16}

W. R. Deal and G. E. Stuber

The new oxygen-16 electrolysis system was put into operation during the fourth quarter of 1979. Most of the initial problems associated with the start-up of the system have been solved. Approximately $11 \mathrm{~kg}$ of oxygen-16 gas has been produced. A spare part inventory is being procured.

Improvements to the original cold trap design are being made. These improvements will permit operation of the system with less operator attention.

\section{Oxygen-17/18}

G. E. Stuber

The system used to electrolyze water enriched in oxygen-17 or oxygen-18 produced $120 \mathrm{~g}$ of 508 oxygen-17 and $394 \mathrm{~g}$ of $95 \%$ oxygen-18 gas. The cold trap installed in the hydrogen line has decreased the loss of feed water from approximately $10 \%$ to $7 \frac{8}{3}$.

Changes in the operation procedures are expected to result in additional improvements in the yield of future conversion runs.

\section{Xenon}

W. J. ROOS

During this period the following approximate quantities of materials were produced: 0.875 STP liter $20 \%$ xenon-124; 0.720 STP liter $40 \%$ xenon-124; and 8.75 STP 1iters 80 \% xenon -136 .

\section{Low temperature research}

\section{Hydrogen intermolecular potential functions}

\section{G. T. McConville}

Hydrogen occurs in two nuclear spin states, ortho and para hydrogen. At low temperatures para has a total momentum quantum number of $\mathrm{J}=0$ and is spherically symmetric, while ortho has a quantum number of $\mathrm{J}=1$ and has a quadrupole moment. To determine 
the potential for the general angular dependent case, we are first characterizing the para or $J=0$ case by studying its intermolecular potential function.

We have compared potentials to three types of data for para $\mathrm{H}_{2}$ : second virial coefficients; total and differential scattering cross sections; and bound state energies for the $\left(\mathrm{H}_{2}\right)_{2}$ di-molecule. The potentials we have studied are: Exp-6 with Mason-Rice parameters [1], beam potential of Farrar and Lee [2], and Hartree-Fock Dispersion forms proposed by Ahlrich, et al [3], Bauer, et al [4], and Silvera and Goldman [5]. The shapes of these potentials are shown in Figures II-1 and II-2. They differ considerably. The Exp- 6 parameters were determined from high temperature second virial and transport property data. The Silvera and Goldman form was determined from beam and solid state data. The others were determined from beam data only.

We show first the fit to the high temperature second virial for para $\mathrm{H}_{2}$, in Figure II-3. The Exp-6, as expected, fits the data, while none of the beam potentials do. At low temperatures the difference between the para $\mathrm{H}_{2}$ and normal $\mathrm{H}_{2}$ ( $75 \%$ ortho) can be seen. In Figure II-4, it can be seen that the Exp-6 and the Bauer potentials are too high; Ahlrich is low at all temperatures. Silvera and Goldman produce a good, low temperature fit but a poorer, high temperature fit.

The energy levels for $\left(\mathrm{H}_{2}\right)_{2}$ bound states depend on the shape of the attractive well of the potential. There are two bound states: one for angular momentum $L=0$, and one for $L=1$. The energy difference between these levels was observed spectroscopically by McKeller and Welsh [6]. The $\mathrm{L}=0$ state is the only one occurring in para $\mathrm{H}_{2}$. The calculated energies are compared to the experimental differences in Table II-1. The bound state energies are determined by the negative energy necessary to produce a wave function meeting the boundary condition that it goes to zero at large distances. The wave functions are generated through a numerical integration of the schrodinger equation. It can be seen from the table that only the Evett and Margenau value lies within the experimental range. This is surprising because the Evett and Margenau potential was calculated in 1953 and contains incorrect dispersion parameters. None of the potentials produces experimental virials and bound state energies simultaneously.

The potentials of Ahlrich, Bauer, and Farrar and Lee were produced from beam measurements. Preliminary calculations of non-velocity-averaged, differential scattering cross sections show that the three potentials are not reconcilable to the data of Farrar and Lee. Calculations of the total cross sections to compare with the work of Bauer are in progress.

The problem is to find a potential function that will represent the three different types of data. The Hartree-Fock Dispersion form of the potential can make use of theoretically determined parameters.

The form introduced by scoles is:

$$
\begin{array}{cl}
Q(r)= & A e^{-\alpha r}-\left(\frac{C_{6}}{r^{6}}+\frac{C_{8}}{r^{8}}+\frac{C_{10}}{r^{10}}\right) f(r) \\
f(r)= & \exp -\left(D \frac{r m}{r}-1\right)^{2} r<r_{m} \\
f(r)=1 & r \geq r_{m} .
\end{array}
$$




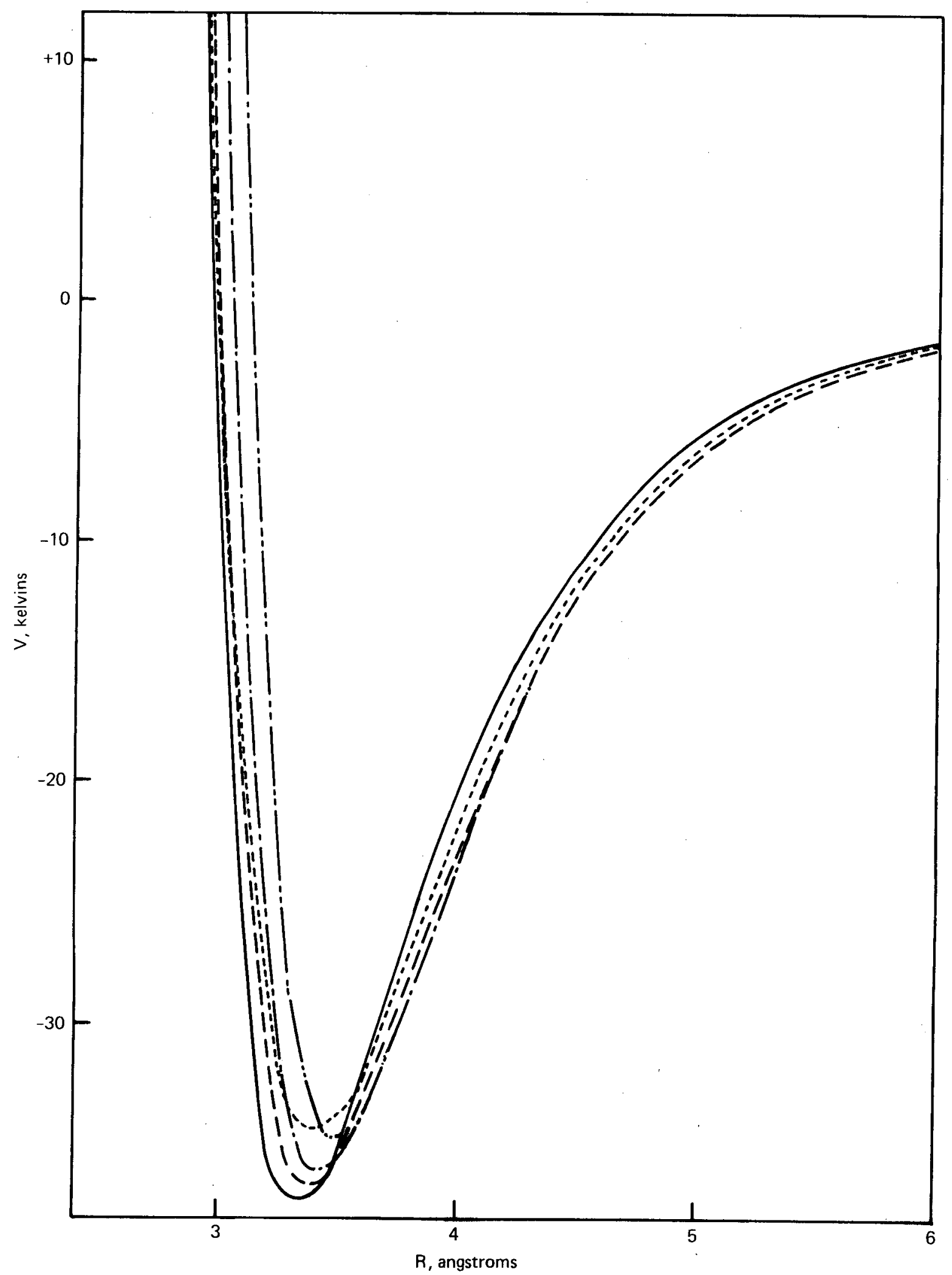

FIGURE II- - A Atractive portion of five $\mathrm{H}_{2}$ potentials: - Exp-6 (MasonRice); --Ahlrich, et a 1; - - Silvera and Goldman; -.-Bauer, et al; ---Farrar and Lee. 


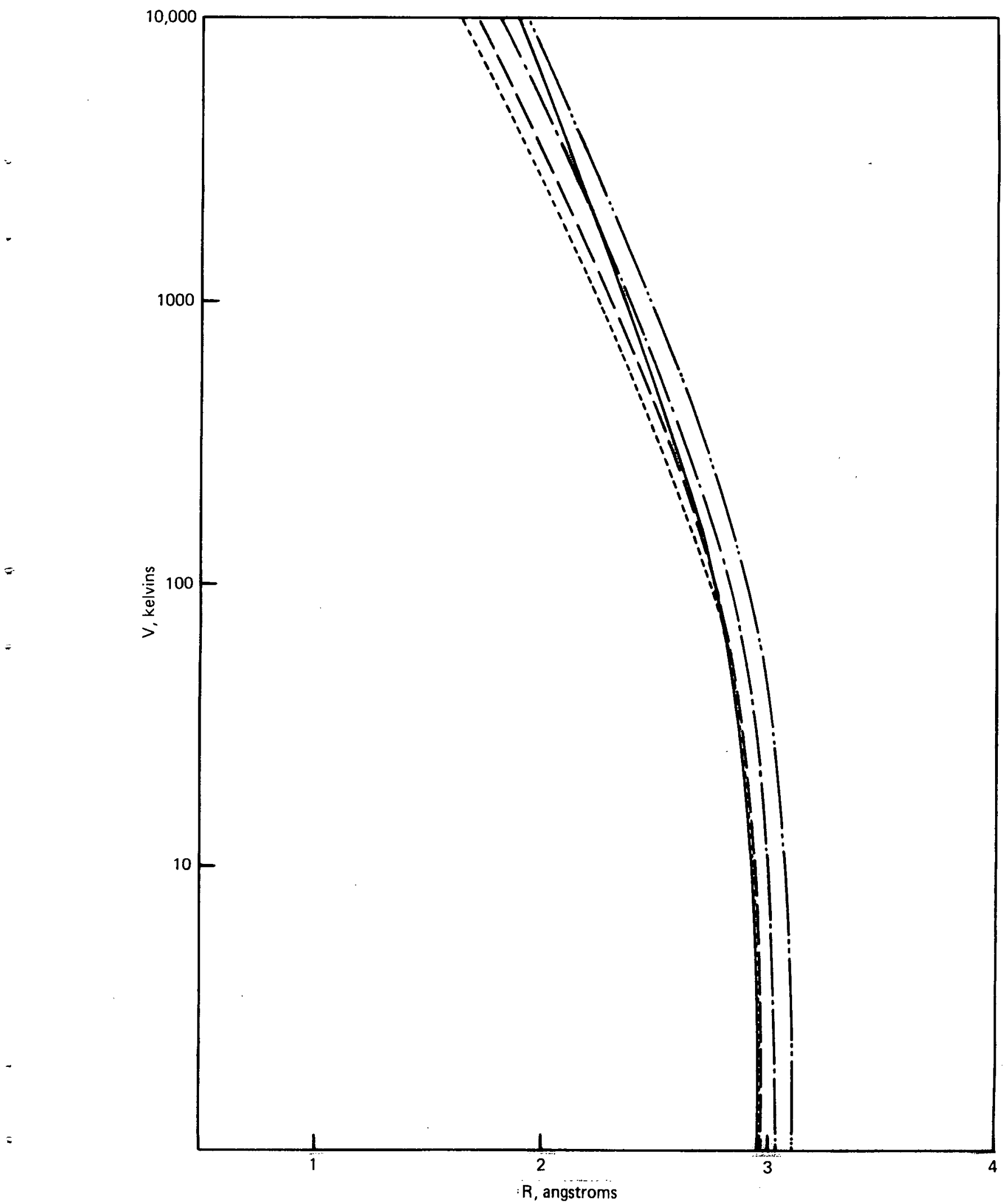

FIGURE II -2 - Repulsive portions of five $\mathrm{H}_{2}$ potentials: Legend same as Figure II -1.

11 


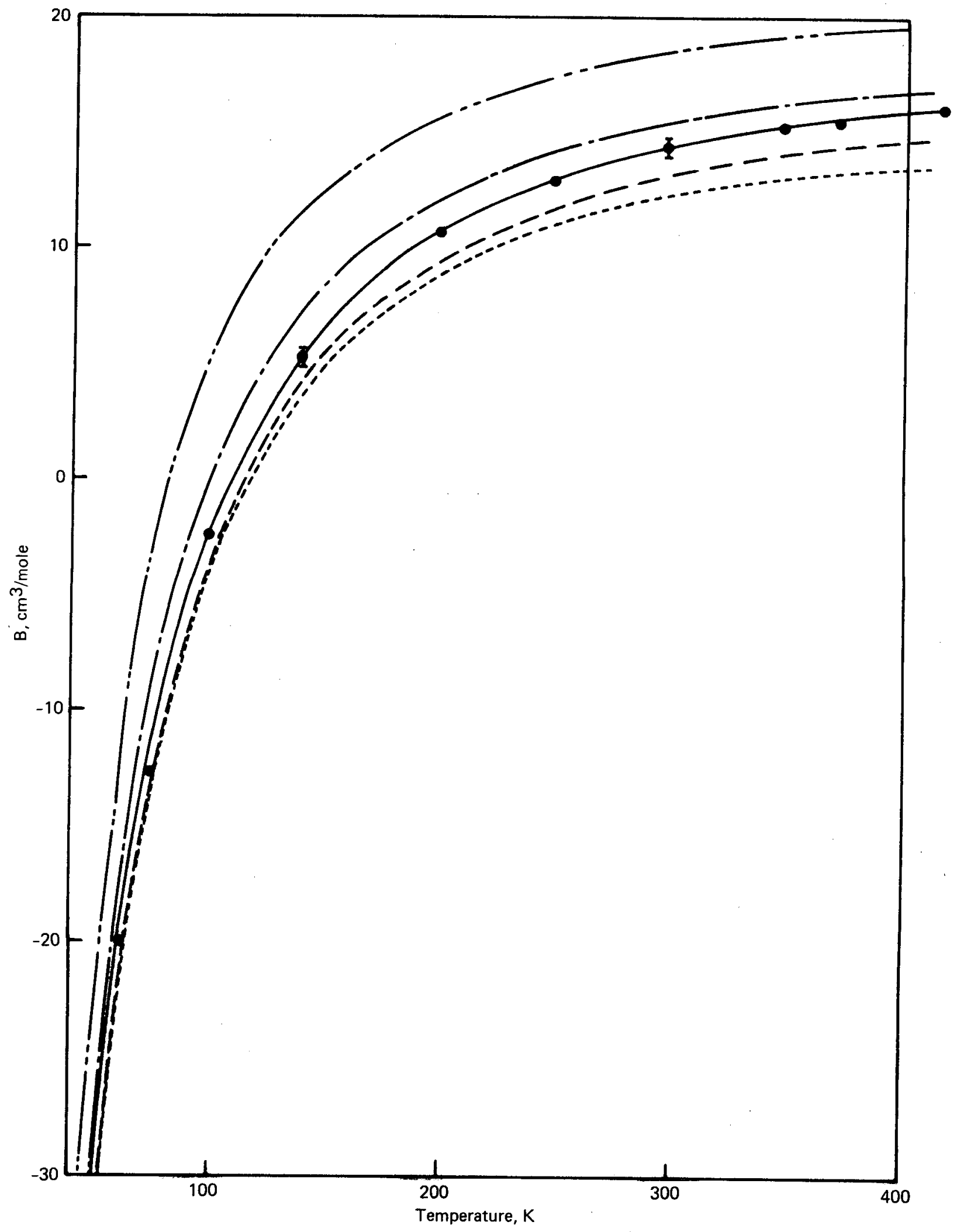

FIGURE II-3 - High temperature second virial coefficients for $\mathrm{H}_{3}$. Experimental: $\bullet$ normal $\mathrm{H}_{2}$ (difference from para $\mathrm{H}_{2}$ within experimental uncertainty $\Phi)$. Theoretical: legend same as Figure 1 . 


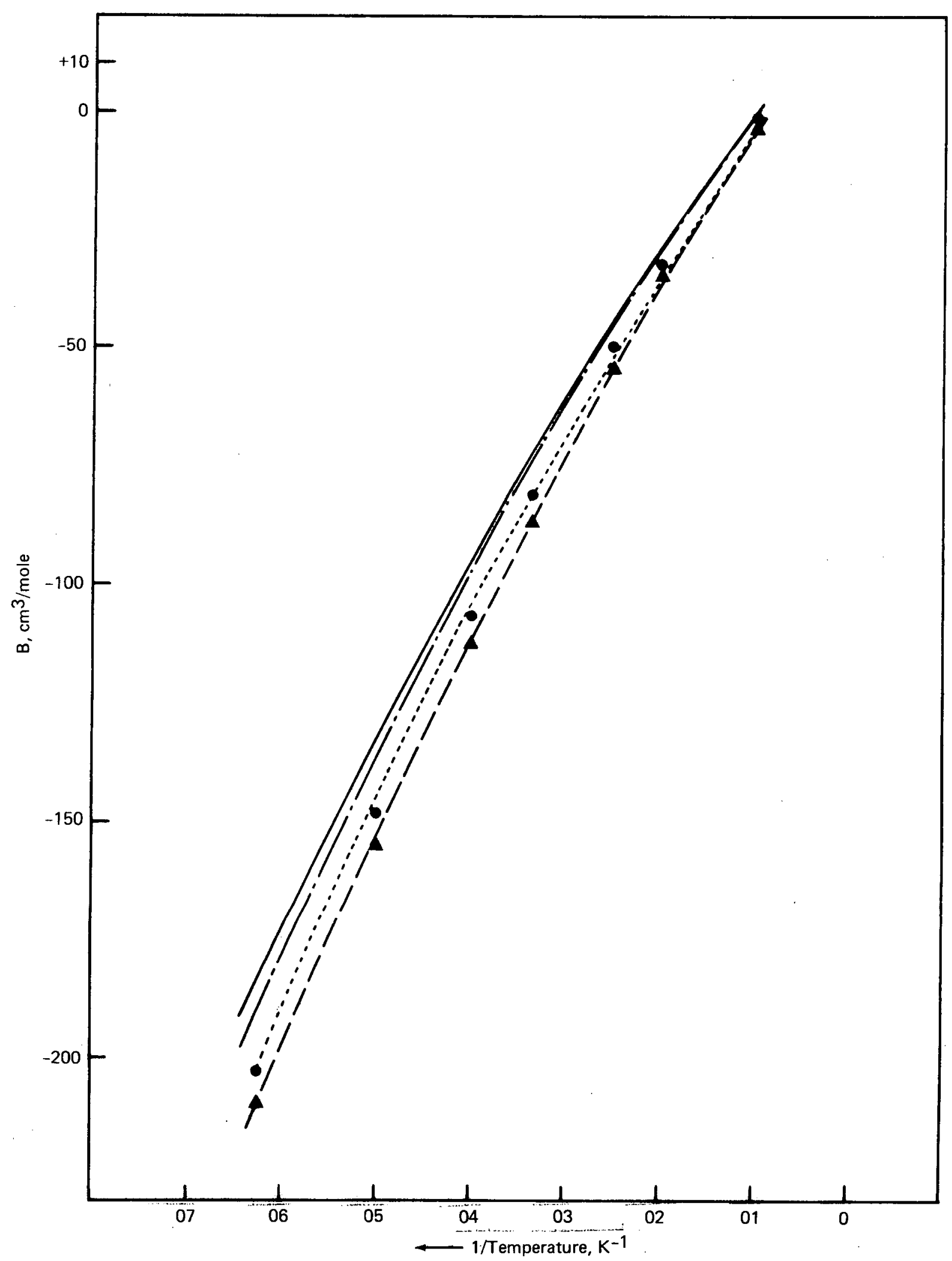

FIGURE II-4 - Low temperature second virial coefficients for $\mathrm{H}_{2}$. Experimental: - para $\mathrm{H}_{2}$ (spherically symmetric); $\boldsymbol{\Delta}$, normal $\mathrm{H}_{2}(75 \%$ ortho-25\% para). Theoretical curves (legend same as Figure II-l) are to be compared with the $\bullet$ para $\mathrm{H}_{2}$ data. 
Experimental

McKellar \& Welsh (1974)

Calculated

Gordon \& Cashion 7 (1965)

$$
\text { L-J }
$$

Exp-6 (Mason-Rice)

Exp-6 (Evett-Marganau) 8

McKellar \& Welsh (1974)

Beam (Farrar \& Lee) 1

McConville (this work)

Exp-6 (Mason-Rice)
Beam (Farrar \& Lee) 1
Beam (Ahlrich, et al) 2
Beam (Bauer, et al) 3
Silvera \& Goldman 4

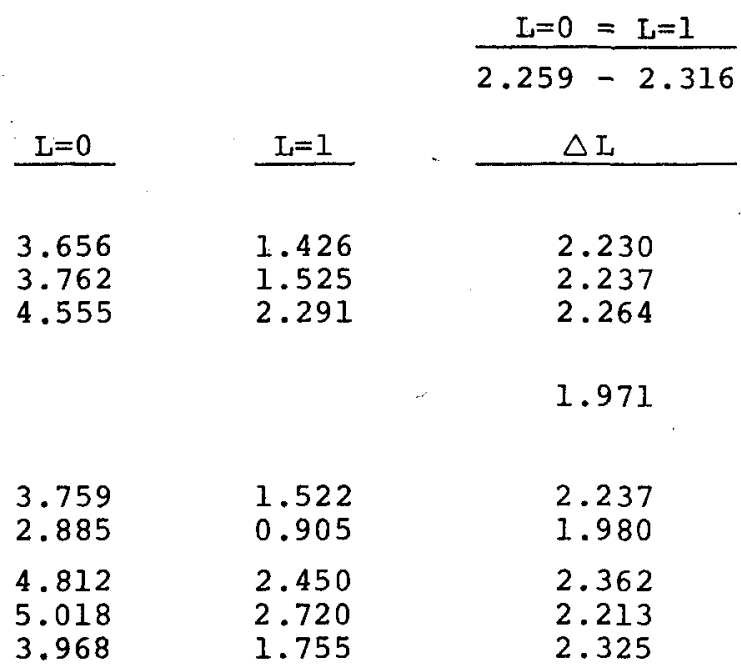

The values of $A$ and $\alpha$ are obtained from self-consistent Hartree-Fock calculations for the $\left(\mathrm{H}_{2}\right)_{2}$ system; the $\mathrm{C}_{2 \mathrm{n}}$ are obtained from Rayleigh-Schrodinger perturbation calculations. For the potential of Ahlrich [3], $A=3.9788 \times 10^{6} \mathrm{~K}$, and $\alpha=3.349 \AA^{-1}$ from the self-consistent field HartreeFock calculations of $W$. Meyer [9]. New values for $C_{6}, C_{8}$, and $C_{10}$ of $12.2,213$, and 4700 , respectively, in atomic units have been calculated in a second paper by Meyer [10]. Ahlrich used a value of 1.28 for $D$ which he assumed to be a universal parameter for spherical systems. We have found [9] that $D=1.24$ is necessary to obtain an accurate potential for helium. The difference between $D=1.28$ and $D=$ 1.24 using Ahlrich's other parameters for $\mathrm{H}_{2}$ is shown in Figure II-5. D represents a parameter measuring the effect of electronic overlap of the two molecules and is the most difficult to obtain from theory. The effect of changing $D$ on the experimental properties is under study. It is possible that a different value of $D$ is required for each multiple term in the dispersion expansion.
A low temperature differential calorimeter has been designed and constructed with the assistance of a University of Cincinnati Co-op student, Janice Fair. The measurement of vapor pressure and heat capacity on the same gas samples can produce a precise value of the latent heat of vaporization at $T=0$. This quantity is one of the two solid state parameters used to obtain a self-consistent potential function for all three phases: solid, liquid and gas. The calorimeter and associated ${ }^{3}$ He refrigerator are shown in the next three figures. The cryostat, shown in Figure II-6, has two recirculating ${ }^{3} \mathrm{He}$ refrigerators which were designed and built by W. R. Wilkes [11]. The platform on top of the cryostat (top of Figure II-6) holds the bellows for a pneumatically driven heat switch. In Figure II-7 the $1.5 \mathrm{~K}^{3} \mathrm{He}$ refrigerator is in the copper tube on the feedthrough flange at the center of the figure. The $0.3 \mathrm{~K}{ }^{3} \mathrm{He}$ pot is the cylinder supported by 1/8-in. diameter stainless rods from the electrical feedthrough flange. The calorimeter itself is shown in Figure II-8. The twin calorimeter cans 


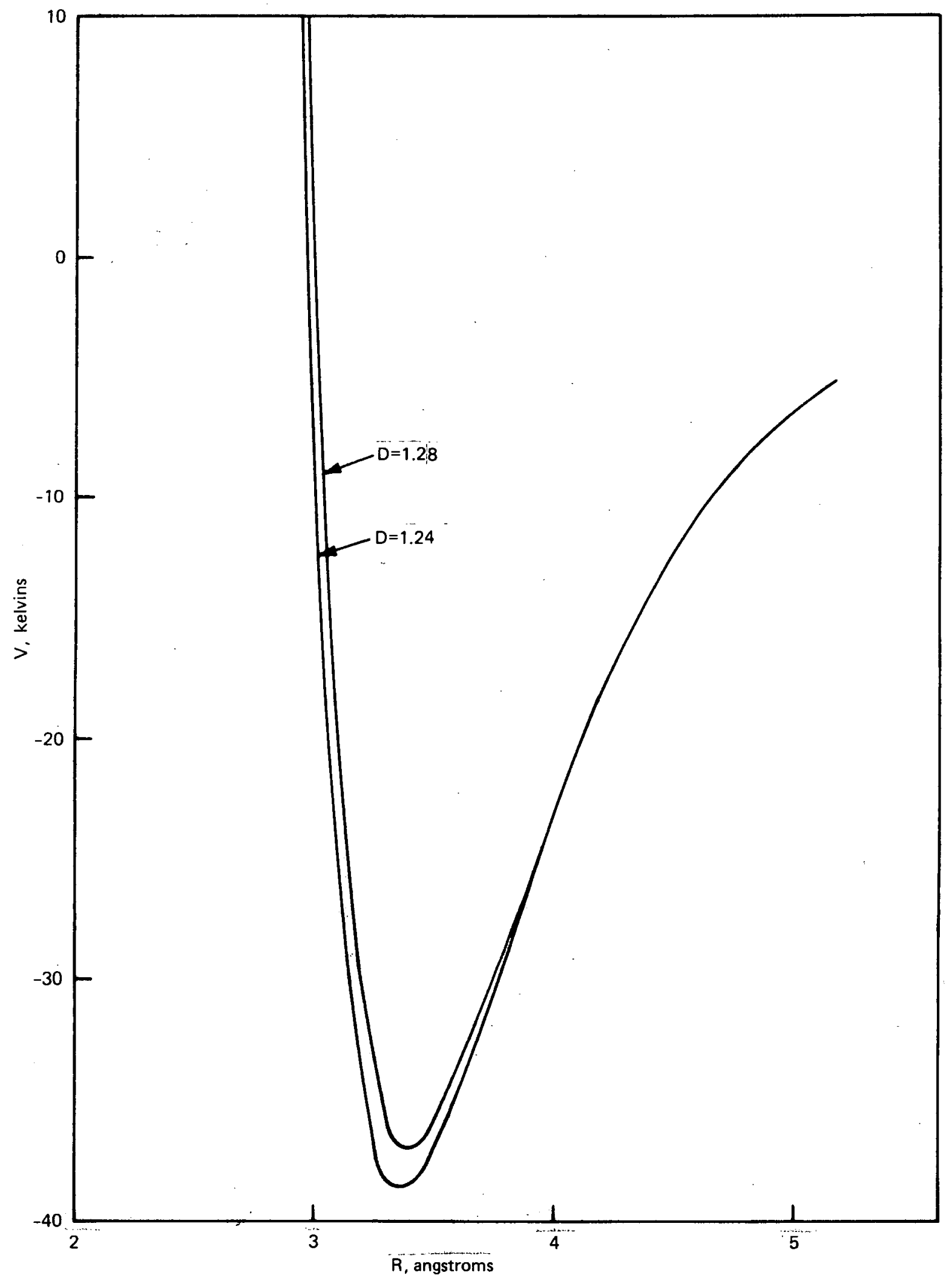

FIGURE II-5 - Hartree-Fock dispersion potential of Ahlrich, et al, with variation of parameter $D$. Reduction of $D$ increases depth of well and reduces collision diameter. 


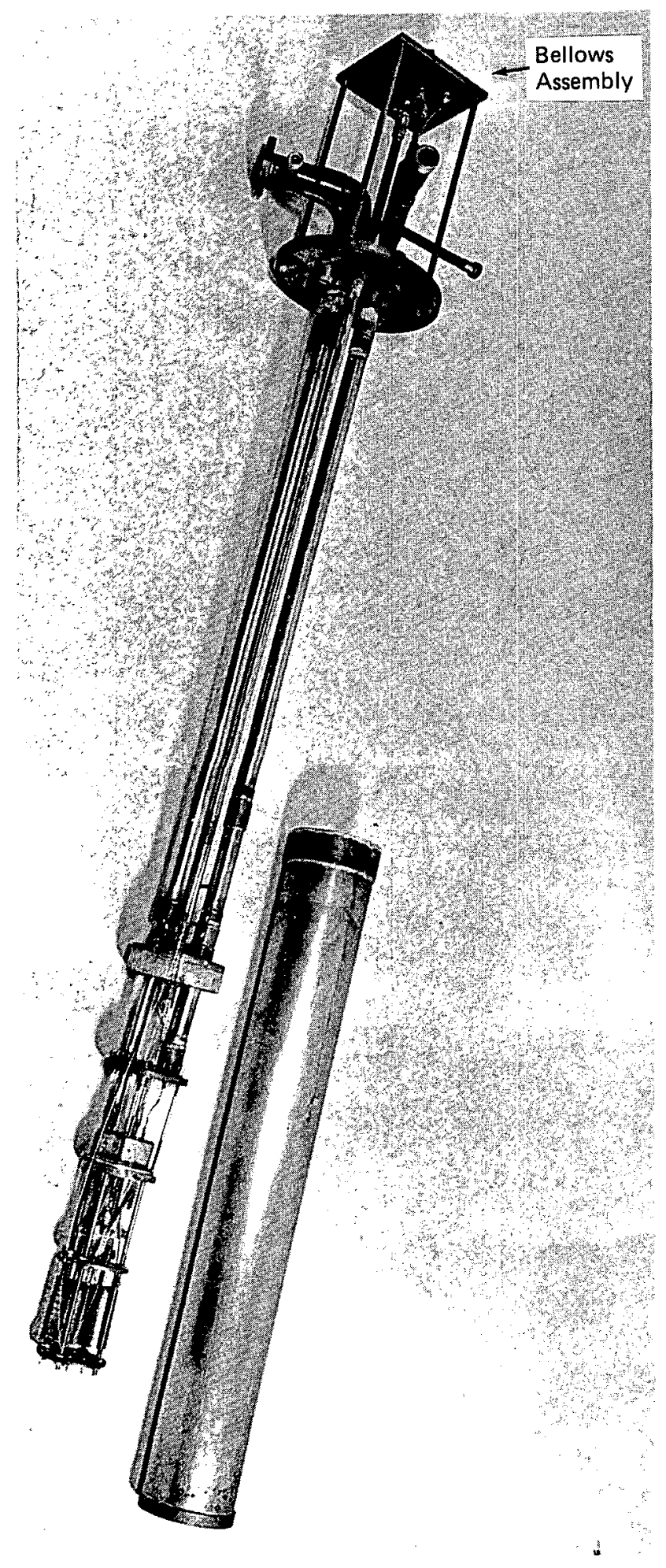

FIGURE II- 6 - The cryostat for 10 temperature differential thermometer. Bellows assembly operates heat switch.

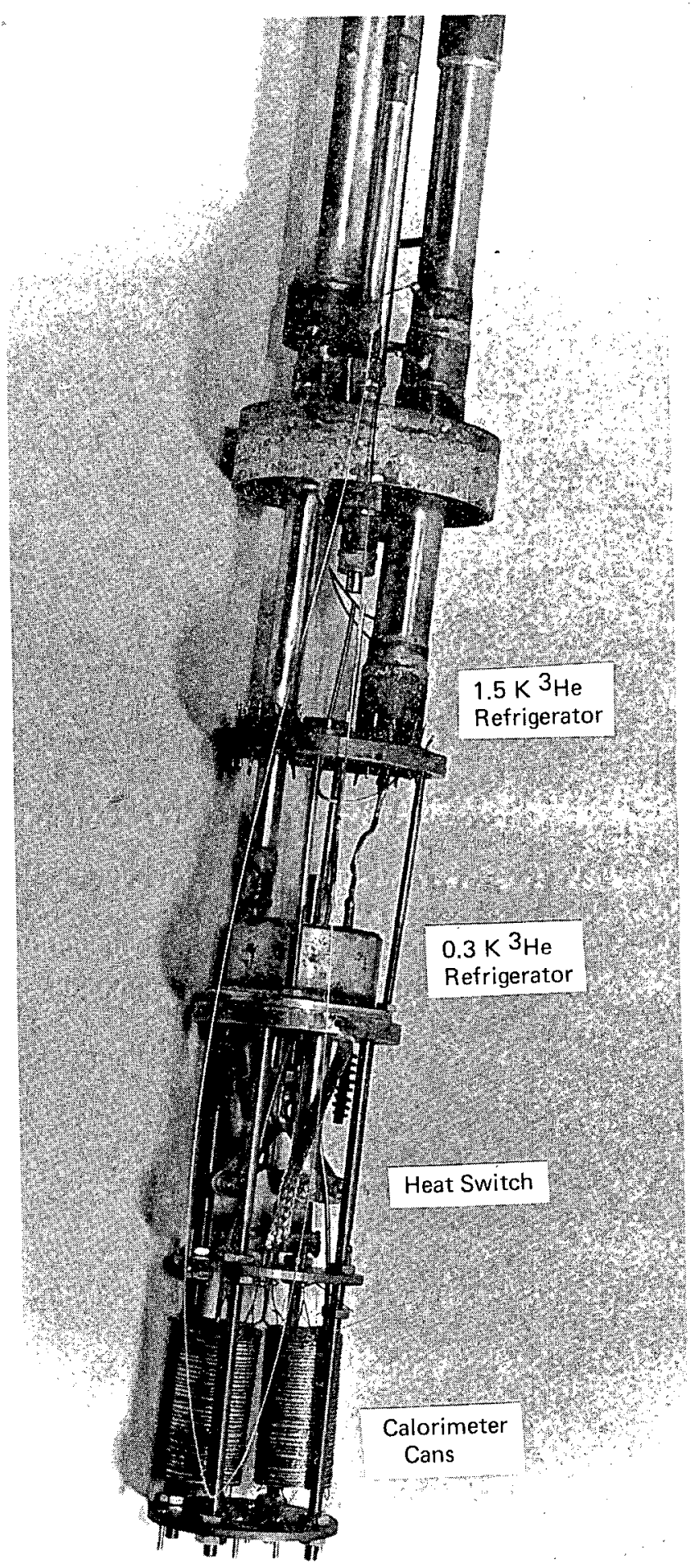

FIGURE II-7 - Low temperature end of cryostat shown in Figure II- 6 . 


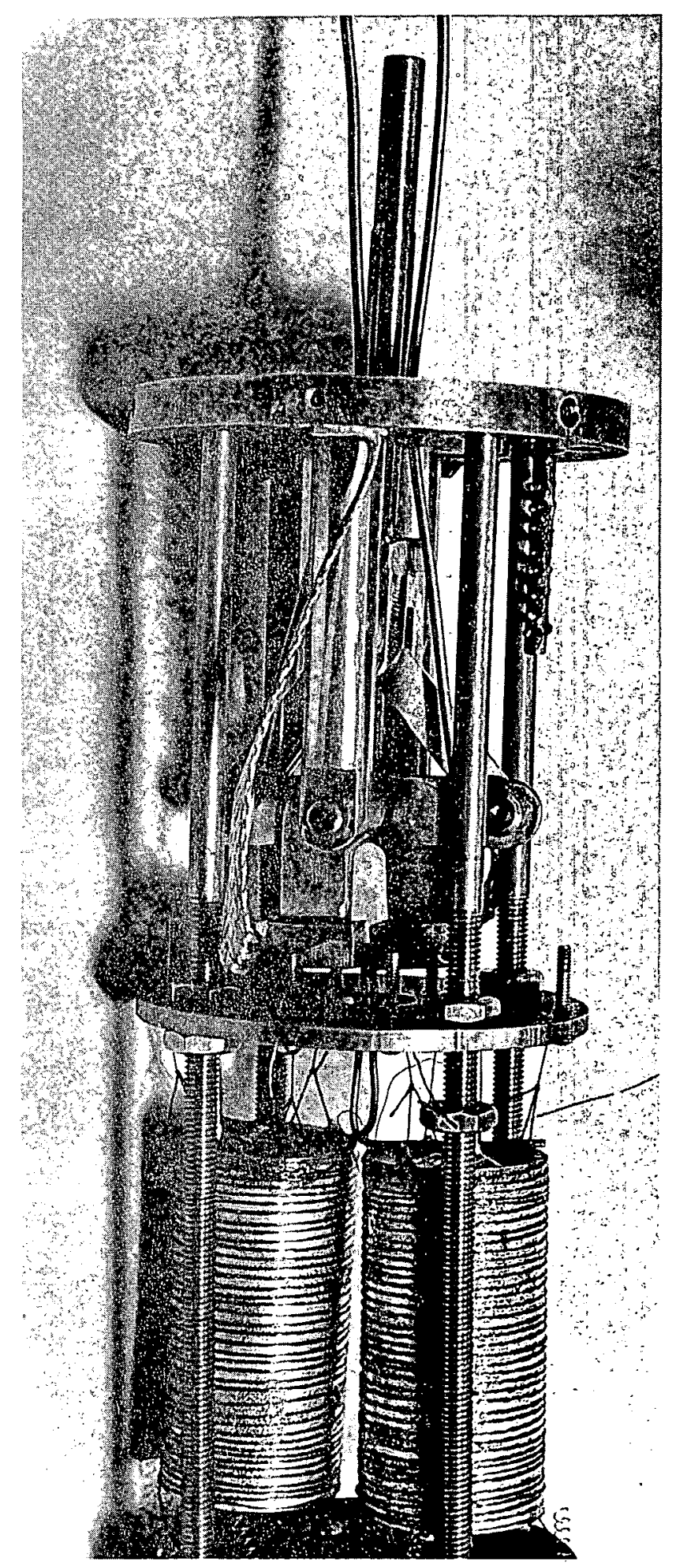

FIGURE II-8 - CToseup of heat switch as sembly and calorimeter cans. are cooled by copper wires clamped in goldplated copper jaws; this is accomplished when the heat switch in the center of the picture is activated by pulling upon the central rod with the bellows mechanism. The samples are thermally isolated by releasing the jaws. The cryostat is now being electrically wired and the gas handling systems for the ${ }^{3} \mathrm{He}$ refrigerators and samples are being built.

\section{Low temperature trennschaukel}

D. Cain and W. L. Taylor

An accurate analytical technique is being developed for the in situ analysis of gas mixtures in low temperature trennschaukel experiments. The method employs selfheated thermistors as sensing elements; two are to be immersed in the unknown gas mixture, while two others are in a known reference gas. The pairs of thermistors form opposite arms of a Wheatstone bridge. When sufficient current is passed through the bridge, the temperaure of the thermistors rises above that of the ambient gas due to Joule heating. The temperature, and therefore the resistance, of the thermistors is determined in the main by the ability of the surroundings to carry off heat. Thus, the resistance values in the arms of the bridge change with the thermal conductivity of the gas mixture, which in turn changes with gas composition. For a given temperature, bridge current, and reference gas, the amount of imbalance in the bridge is a measure of the composition of unknown gas. 
Before installing the thermistors into the trennschaukel for in situ measurements, it was decided that the technique should first be demonstrated on the bench. Several sets of thermistors and associated electronics and hardware have been assembled for construction of a thermal conductivity gas analyzing bridge. An insulated box was fabricated in the shop to serve as an environmental chamber for the bridge. The bridge elements and gas mixtures (unknown and reference) were sealed into enclosures which are immersed in a water bath in the environmental chamber. A constant temperature circulator (Haake, Model FSEl controls the temperature of the bath, and, thereby, the environmental chamber. Millikelvin temperature control over a period of one hour has been achieved in the water bath; with fluctuations in the air around the bath somewhat larger."The power supply, digital voltmeter, standard resistor, and any other device that may be temperature sensitive are all kept in the temperature-controlled environment.

The bridge must be calibrated for each gas mixture of interest at constant (and known) temperature and bridge current. To this end, we have had prepared gas mixtures of accurately known composition over the range of compositions expected to be encountered. The reference gas will be introduced into both the cell which is to contain the reference thermistors and the one which is to contain the unknown thermistors. Under ideal conditions of perfectly matched thermistors, all resistances would be equal, and the bridge would be balanced; in reality, the bridge will show a small imbalance. Keeping the same reference gas in the reference cell, other known gas mixtures will be introduced into the unknown cell, and the amount of imbalance recorded. In this way, we can generate a calibration curve which can later be used with the reference gas and a true unknown mixture. A thermistor bridge of this type has been shown to be as sensitive as a dual collector mass spectrometer for analyzing mixtures of ${ }^{36} \mathrm{Ar}-{ }^{40} \mathrm{Ar}$; for $\mathrm{Ar}-\mathrm{Kr}$ and Ne-Ar mixtures it is seven and ten times more sensitive, respectively [12].

Thermistors suitable for use at cryogenic temperatures have been obtained for installation into the trennschaukel. The trennschaukel has 12 tubes, one of which will be sacrificed for a reference cell, leaving 11 for the swing separation.

After installing the thermistors, heater wires, and platinum resistance thermometers, the thermistors will be calibrated for the gas mixtures of interest under experimental conditions. This will allow concentration changes to be monitored in situ in a thermal diffusion experiment.

The systems of interest for the present work are $\mathrm{He}-\mathrm{Ne}$ and ${ }^{3} \mathrm{He}-{ }^{4} \mathrm{He}$. Experiments will be conducted from approximately $250 \mathrm{~K}$ down to $25 \mathrm{~K}$ (or as low as the system will go). In addition, the bench system on which the technique is demonstrated will remain intact for use in analyzing gas mixtures from mutual diffusion experiments and other trennschaukel systems.

\section{Separation chemistry}

\section{Thorium-229}

\section{W. R. Deal}

Previously extracted uranium-233, in the form of $\mathrm{U}_{3} \mathrm{O}_{8}$ with low uranium-232 content, was processed during the reporting period to produce thorium-229 as two items, 
79-2 (4.1 mg) and $79-3(2.7 \mathrm{mg})$. Item

79-1 (4.1 $\mathrm{mg}$ ) was reported in the previous semiannual report. The total thorium-229 production for the fiscal year was 10.9 mg, meeting the FY-1979 commitment.

Further discrepancies between the expected isotope ratios and the results received from mass spectrometry indicate that previous extractions of this feed material did not remove all the natural thorium present, a factor that must be considered in the prediction of future isotope ratios. This process will be suspended for FY-1980. Future demand for thorium-229 will determine whether or not the process is reactivated. The facility was placed on standby and all the feed material was returned to storage.

\section{Protactinium-231 and Thorium-230}

M. L. Hertz and P. E. Figgins

Mound Facility recovers thorium-230 and protactinium-231 from a uranium mill byproduct known as "Cotter Concentrate" and ships the products to Isotope Sales at ORNL. Previous reports contain detailed descriptions of the origin and character of the cotter Concentrate, the processing facilities, and development of the current recovery and purification processes.

This process has been suspended for FY-1980. Therefore, head-end processing of cotter Concentrate was discontinued in June 1979 to allow time for complete processing of the separated protactinium concentrate by the end of FY-1979. The systems were cleaned up as much as possible without complete dismantling, and left ready for re-start on short notice, if desired.
A total of $101.4 \mathrm{mg}$ of protactinium-231, as estimated by gamma analysis, was separated from the cotter Concentrate, concentrated by evaporation and passed on to the final purification process. The concentrate solutions were purified by the standard method, and two protactinium products obtained. The first contained $116 \mathrm{mg}$ of protactinium-231 (by alpha count) and weighed $143 \mathrm{mg}$. The second, which was kept separate because of suspected impurities, contained $16.2 \mathrm{mg}$ of protactinium231 and weighed $29.7 \mathrm{mg}$. These products, along with $56,920 \mathrm{mg}$ of thorium-230, were shipped to ORNL and comprise the FY-1979 product.

Installation of a Westfalia centrifuge was completed in October 1979. An initial "cold" checkout will be made, after which the unit will be available for future use in clarifying the dissolved cotter concentrate, if the process should be re-started.

\section{Uranium-234}

P. L. Keister

Mound Facility has been separating and recovering high-isotopic purity uranium234 from aged plutonium-238 since 1964 . The chemical steps have been described elsewhere in detail [1].

The intermediate separation (anion exchange in nitrate media) of uranium from the second half of the uranium-rich A20 filtrate was completed during this period. The filtrate had been salted to $1.6 \mathrm{M}$ with $\mathrm{Al}\left(\mathrm{NO}_{3}\right)_{3}$ and adjusted to $0.3 \mathrm{M} \mathrm{HNO}_{3}$ using $\mathrm{NH}_{4} \mathrm{OH}$. Hydroxylamine nitrate was added as a reductant for plutonium, and the salted feed was loaded on to the column of Dowex $1 \times 4$ anion 
exchange resin (nitrate form). The uranium was eluted with $7 \underline{\mathrm{M}} \mathrm{HNO}_{3}$, and the plutonium was eluted with $0.35 \underline{\mathrm{M}} \mathrm{HNO}_{3}$ containing hydroxylamine nitrate. Alpha pulse height analyses of samples from the uranium fractions indicated a total of $10.4 \mathrm{~g}$ of uranium-234 with $16 \mathrm{mg}$ of plutonium238 .

To prepare for the final separation step (anion exchange in chloride media), these uranium fractions were combined and converted to chloride form by a double precipitation with $\mathrm{NaOH}$ and subsequent dissolution in $9 \mathrm{M} \mathrm{HCl}$. Two runs were made to complete the final separation of $\mathrm{A} 20$. The chloride solution was loaded onto the column of Dowex $1 \times 4$ anion exchange resin (chloride form). The plutonium was eluted with $9 \mathrm{M} \mathrm{HCl} / 0.05 \mathrm{M} \mathrm{NH}_{4} \mathrm{I}$. A neptunium fraction was eluted with $4 \underline{M} \mathrm{HCl}$, and the uranium was eluted with $0.5 \mathrm{M} \mathrm{HCl}$. Alpha pulse height analyses of samples from the uranium fractions indicated a total of $9.1 \mathrm{~g}$ of uranium-234 with 5-6 ppm plutonium-238.

These A20 uranium fractions were combined, the uranium precipitated with $\mathrm{NH}_{4} \mathrm{OH}$, and the precipitate calcined to the oxide at $900^{\circ} \mathrm{C}$. The total oxide weight of the final A20 product was $10.811 \mathrm{~g}$. Final alpha pulse height analyses of samples indicated $12.7 \mathrm{ppm}$ uranium-232 and $2.3 \mathrm{ppm}$ plutonium-238 by weight. Based on alpha pulse height data and proportional counting of samples, the uranium-234 content was calculated at $8.884 \mathrm{~g}$. Mass analysis of the sample indicated the final A20 product had an isotopic purity of $99.855 \%$ by weight.

Because product A20 did not meet the FY1979 goal of $10.0 \mathrm{~g}$ of uranium-234 product, another aged plutonium "cow" was selected for processing. This "cow" was designated batch $A 21$ and contained $19 \mathrm{~g}$ of plutonium238 with an estimated $3.1 \mathrm{~g}$ of uranium-234 based on an age of 18 years. It was received from storage in the form of encapsulated metal which had been fabricated for a heat source. The capsule was opened with a hacksaw, and the plutonium metal dissolved in hot, concentrated $\mathrm{HNO}_{3}$ containing 0.05 to $0.1 \mathrm{M} \mathrm{MF}$. The plutonium was precipitated as the oxalate using dimethlyoxalate. The oxalate precipitate was calcined and the plutonium returned to storage as the oxide.

The uranium-rich A2l filtrate was evaporated to concentrate the volume and to destroy the oxalate. Alpha pulse height analyses of samples indicated $3.9 \mathrm{~g}$ of uranium-234 and $0.7 \mathrm{~g}$ of plutonium-238. The intermediate separation, the final separation, and the final product preparation of batch A21 were completed as described above for A20. The total oxide weight of the final uranium product was $4.241 \mathrm{~g}$. The weight of the uranium-234 was calculated at $3.473 \mathrm{~g}$ with $9.9 \mathrm{ppm}$ uranium-232 and $3.8 \mathrm{ppm}$ plutonium-238 by weight. The isotopic purity of product A21 was 99.6348 by weight.

Table III-l summarizes products shipped in FY-1979.

Table III-I - URANIUM-234 PRODUCTS SHIPPED (FY-1979)

\begin{tabular}{|c|c|c|c|}
\hline Product & $\begin{array}{c}234 \mathrm{U} \\
(\mathrm{g})\end{array}$ & $\begin{array}{l}238 \mathrm{Pu} \\
\text { (ppm) }\end{array}$ & $\begin{array}{l}\text { Isotopic } \\
\text { Purity } \\
\text { (wt } z \text { ) }\end{array}$ \\
\hline A20 & 8.884 & 2.3 & 99.855 \\
\hline \multirow[t]{2}{*}{ A2 1} & 1.116 & 3.8 & 99.634 \\
\hline & 0.000 & & \\
\hline
\end{tabular}




\section{Separation research}

\section{Liquid thermal diffusion}

W. M. Rutherford

Experimental and theoretical work continued on the performance of Iiquid phase thermal diffusion columns for isotope separation. Construction and preliminary testing of a new research column were described in the last report [1]. The design of the new column incorporates a number of features derived from the results of extensive experimental work with a variety of simply constructed practical scale devices. The first measurements on chlorine isotope separation in the chlorobenzene system were in good agreement with theory at a hot-to-cold wall spacing of $254 \mu \mathrm{m}$. This report describes the results of additional work at other spacings and with other compounds. New experimental methods were devised to accelerate the rate of data acquisition, and computer programs were developed to process the resulting experimental data.

The separation of a binary mixture in a thermal diffusion column is described by the following equation for the net transport of component 1 in the vertical, $z$, direction

$$
\tau_{1}=\mathrm{Hw}_{1}\left(1-\mathrm{w}_{1}\right)-\mathrm{K} d \mathrm{w}_{1} / \mathrm{dz}
$$

where $\tau_{1}$ is the transport in mass per unit time and $w_{1}$ is the mass fraction of the component. The quantities $H$ and $K$ are the initial transport coefficient and the remixing coefficient, respectively. The column coefficients are complicated functions of the dimensions and operating conditions of the column and of the properties of the fluid. Simple, approximate expressions can be derived for the case of a Boussinesq fluid with constant average properties at the mean temperature of the column. Thus,

$$
\begin{aligned}
& H=\frac{a^{3} \rho^{2} \alpha_{T} \beta g B\left(T_{H}-T_{C}\right)^{2}}{6 ! n \bar{T}} \\
& K=\frac{a^{7} g^{2} \beta^{2} \rho^{3} B\left(T_{H}-T_{C}\right)^{2}}{9: \eta^{2}} .
\end{aligned}
$$

$$
\text { where } \begin{aligned}
\mathrm{a} & =\text { hot-to-cold wall spacing } \\
\mathrm{B} & =\text { circumference } \\
\mathrm{g} & =\text { gravitational acceleration } \\
\mathrm{T}_{\mathrm{H}} & =\text { hot wall temperature } \\
\mathrm{T}_{\mathrm{C}} & =\text { cold wall temperature } \\
\overline{\mathrm{T}} & =\text { average temperature } \\
\alpha_{\mathrm{T}} & =\text { thermal diffusion factor } \\
\eta & =\text { viscosity } \\
\rho & =\text { density } \\
B & =-\frac{1}{\rho}\left(\frac{\mathrm{d} \rho}{\mathrm{d} t}\right)
\end{aligned}
$$

Diffusive remixing along the $z$ direction is neglected; therefore, the total remixing coefficient is equal to the convective remixing coefficient.

At total reflux $\tau_{1}=0$, and

$$
\ln q_{E}=\ln \frac{w_{1 B}\left(1-w_{1 T}\right)}{w_{1 T}\left(1-w_{1 B}\right)}=H L / K
$$

where $q_{E}$ is the separation factor and $L$ is the length along the column. The subscripts $T$ and $B$ refer to the top and bottom sample points, respectively.

Measurement of the experimental separation at total reflux yields only the ratio $\mathrm{H} / \mathrm{K}$. In order to determine the magnitudes of the individual coefficients, it is necessary to do an experiment for which $\tau_{1} \neq 0$. Such an 
experiment can be one in which a steady state, net flow is imposed on the column, or it can be one in which the transient behavior of the column is observed following start-up from an initially uniform concentration profile. For the latter case:

$$
\frac{\partial w_{1}}{\partial t}=-\frac{1}{\mu}\left(\frac{\partial \tau_{1}}{\partial z}\right)
$$

where $t$ is the time and $\mu$ is the mass holdup per unit length.

In previous work, we have used the steady state technique almost exclusively because of the practical difficulties associated with removing small, representative samples from the experimental columns.

A new experimental system has been devised which solves the sampling problem. As shown in Figure IV-1, each end of the

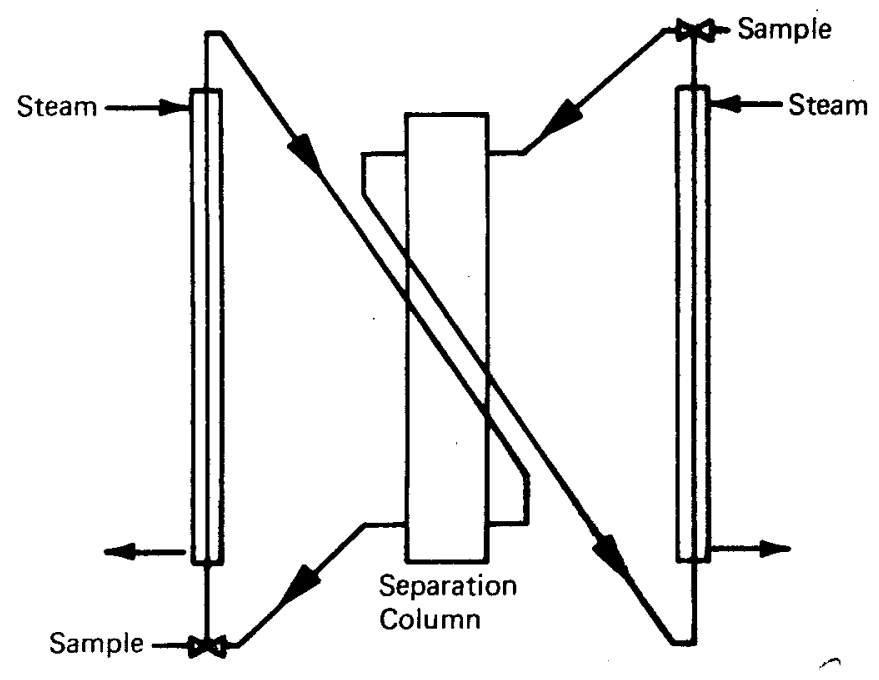

FIGURE IV-1 - Liquid thermal diffusion apparatus for transient separation measurements. column is fitted with a steam heated thermosiphon loop which circulates fluid continuously through the active section of the column. Each thermosiphon loop contains a High Pressure Equipment Co., 3-way, 1/16in., high-pressure valve which serves as a sampling valve. The design of the valve is such that the liquid to be sampled is circulated past the valve seat. Extremely small, representative samples can be removed by evaporating liquid through the valve seat into an evacuated volume. A typical sample volume with this technique is on the order of $5 \mu \mathrm{L}$, as compared to a typical volume of $170 \mu \mathrm{L}$ for the purge and sample technique used previously.

The new experimental procedure required the development of computer programs for reduction of the measurements of separation as a function of time. If we define dimensionless time by:

$$
\Theta=\mathrm{YH} t / \mu \mathrm{L},
$$

where

$$
\mathrm{Y}=\ln \mathrm{q}_{\mathrm{E}^{\prime}}
$$

then Equation 5 becomes, at total reflux

$$
\frac{\partial w_{1}}{\partial \theta}=\left(1-2 w_{1}\right) \frac{\partial w_{1}}{\partial y}+\frac{\partial^{2} w_{1}}{\partial y^{2}},
$$

where

$$
\mathrm{Y}=\mathrm{Hz} / \mathrm{K}
$$

The computer program for calculating transient performance of multicomponent separation systems solves the multicomponent analog of Equation 8. It was revised to generate a family of curves of the form:

$$
\ln q=f(\theta, Y)
$$

with $\mathrm{Y}$ as the parameter. The quantity $\mathrm{q}$ in Equation 10 is the transient value of the separation factor defined for the steady state by Equation 1 . 
Experimental separation data were acquired in the form,

$$
\ln q=f(t)
$$

A computer program was writen to generate a best fit to the data by interpolating among the set of curves represented by Equation 10. The fit was accomplished by simplex minimization of the mean square deviation in in $q$. Parameters of the simplex minimization were $Y, H$, and $a$ time increment, $\delta t$, used to compensate for uncertainty in the starting time of the experiment.

The transient technique was used to determine the transport coefficients of the new research column at hot-to-cold wall spacings from 178 to $304 \mu \mathrm{m}$. Chlorobenzene, l-chloropropane, ethyl bromide and carbon disulfide were used as working fluids. The measurements were based on the ${ }^{35} \mathrm{Cl}-$ ${ }^{37} \mathrm{Cl}$ substituted species for the chlorinated compounds, the ${ }^{79} \mathrm{Br}-{ }^{81} \mathrm{Br}$ species for ethyl bromide and the ${ }^{12} \mathrm{C}^{32} \mathrm{~s}^{32} \mathrm{~s}-{ }^{12} \mathrm{c}^{32} \mathrm{~s}^{34} \mathrm{~s}$ pair for carbon disulfide. The experimental series was completed for chlorobenzene. Work is still in progress on the other compounds. Dimensions and operating conditions for the experimental column are given in Table IV-1.

Some typical raw transient data and the fit thereto are shown in Table IV-2 and Figure IV-2. Table IV-3 is a compilation of the column coefficients for all the experiments. Depending on the hot-to-cold wall spacing and the compound, the time required for each experiment ranged from a little more than $1 \mathrm{hr}$ (ethyl bromide at $304 \mu \mathrm{m}$ ) to 17 days (chlorobenzene at 178 $\mu \mathrm{m})$.

\begin{tabular}{|ll|} 
Table IV-1 - DIMENSIONS AND OPERATING \\
CONDITIONS FOR LIQUID THERMAL DIFFUSION \\
COLUMN EXPERIMENTS \\
Hot wall i.d. & $13.87 \mathrm{~mm}$ \\
Hot wall o.d. & $18.677 \mathrm{~mm}$ \\
& $18.778 \mathrm{~mm}$ \\
& $18.880 \mathrm{~mm}$ \\
& $18.931 \mathrm{~mm}$ \\
& $19.286 \mathrm{~mm}$ \\
Cold wall i.d. & $57.0 \mathrm{~mm}$ \\
Water jacket i.d. & $456 \mathrm{~mm}$ \\
Active length & $164^{\circ} \mathrm{C}$ \\
Steam temperature & $14.4^{\circ} \mathrm{C}$ \\
Water temperature & $9.61^{\mathrm{iters} / \mathrm{min}}$ \\
Water flow rate & \\
\hline
\end{tabular}

In order to calculate the column coefficients from theory, it is necessary to know the temperatures of the hot and cold walls of the working space. These temperatures are only indirectly available from the steam temperature and the inlet temperature of the cooling water. A computer program had been written to do the calculation; however, the program requires an experimentally derived value of the heat transfer coefficient at the column-cooling water interface. A series of thermal measurements was performed, therefore, to evaluate the heat transfer coefficient.

The gross heat flow in the column was determined as a function of water flow rate with the column evacuated in order to get the combined contributions from heat flow through the end seals and heat flow by radiation. The column was then filled with helium, a gas of known thermal conductivity, to determine the contribution of the working space to the heat flow. A value of the heat transfer coefficient, $\mathrm{h}_{\mathrm{w}}$, was selected to get the best match 
Table IV-2 - TYPICAL EXPERIMENTAL DATA FROM TRANSIENT SEPARATION EXPERIMENTS

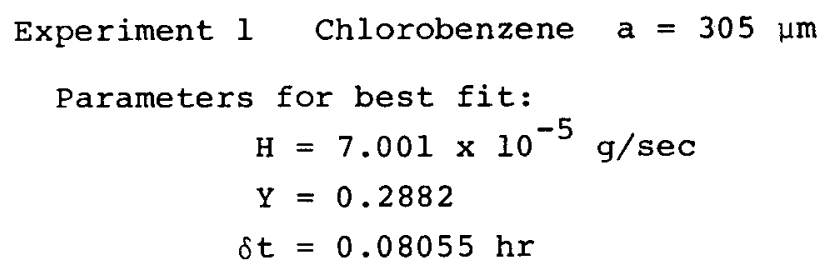

\begin{tabular}{|c|c|c|c|}
\hline$t(h r)$ & $\ln \mathrm{g}$ & $\begin{array}{c}\ln q \\
(\mathrm{calc}) \\
\end{array}$ & Deviation \\
\hline 0.50 & 0.0865 & 0.0878 & 0.0013 \\
\hline 1.00 & 0.1381 & 0.1364 & -0.0017 \\
\hline 2.00 & 0.2001 & 0.2008 & 0.0007 \\
\hline 3.00 & 0.2363 & 0.2377 & 0.0014 \\
\hline 5.00 & 0.2704 & 0.2710 & 0.0006 \\
\hline 7.00 & 0.2819 & 0.2819 & 0.0000 \\
\hline
\end{tabular}

RMS Deviation $=0.0011$

Experiment 2 Chlorobenzene $a=203 \mu \mathrm{m}$ Parameters for best fit:

$$
\begin{aligned}
\mathrm{H} & =1.457 \times 10^{-5} \mathrm{~g} / \mathrm{sec} \\
\mathrm{Y} & =1.230 \\
\delta \mathrm{t} & =0.6524 \mathrm{hr} .
\end{aligned}
$$

\begin{tabular}{|c|c|c|c|}
\hline$t(h r)$ & $\ln g$ & $\ln _{(\mathrm{calc})}$ & Deviation \\
\hline 1.00 & 0.0628 & 0.0775 & 0.0147 \\
\hline 2.00 & 0.1345 & 0.1200 & -0.0145 \\
\hline 5.00 & 0.2385 & 0.2318 & -0.0067 \\
\hline 8.00 & 0.3289 & 0.3284 & -0.0005 \\
\hline 9.50 & 0.3675 & 0.3726 & 0.0051 \\
\hline 24.00 & 0.7000 & 0.7013 & 0.0013 \\
\hline 32.50 & 0.8326 & 0.8323 & -0.0003 \\
\hline 96.00 & 1.1860 & 1.1825 & -0.0035 \\
\hline
\end{tabular}

RMS Deviation $=0.0080$

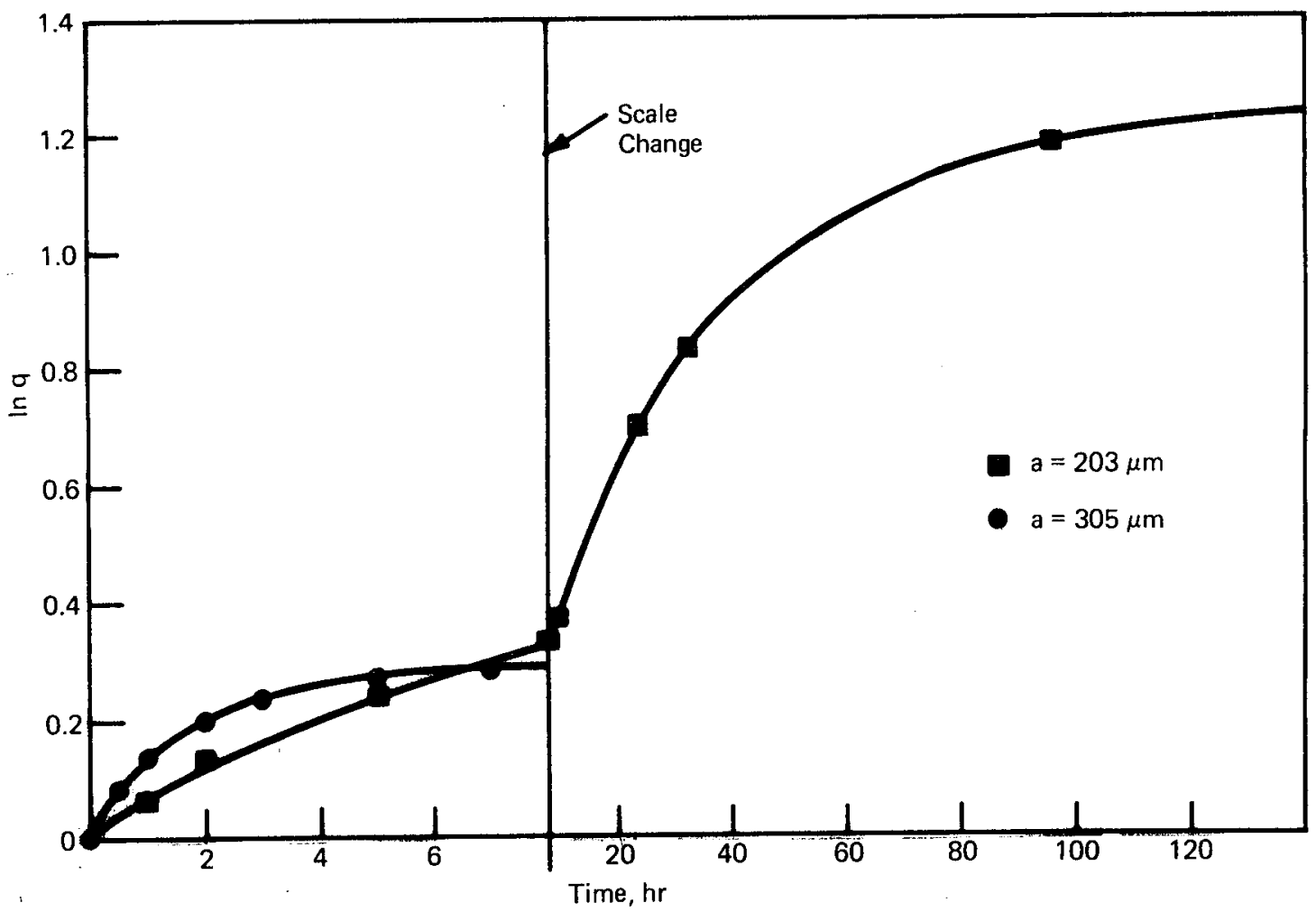

FIGURE IV-2 - Transient separation experiments with chlorobenzene in the liquid thermal diffusion research column. The solid curves are calculated for the best fit. 


\begin{tabular}{|c|c|c|c|c|c|c|c|c|c|}
\hline \multirow[b]{2}{*}{ Compound ${ }^{\circ}$} & \multirow{2}{*}{$\begin{array}{c}a \\
(\mu \mathrm{m}) \\
\end{array}$} & \multicolumn{2}{|c|}{$\frac{\text { Net Heat Flow }}{(\mathrm{W})}$} & \multirow{2}{*}{$\begin{array}{c}\mathrm{T}_{\mathrm{H}} \\
\left({ }^{\circ} \mathrm{C}\right) \\
\end{array}$} & \multirow{2}{*}{$\begin{array}{r}\mathrm{T}_{\mathrm{C}} \\
\left(^{\circ} \mathrm{C}\right) \\
\end{array}$} & \multirow{2}{*}{$\begin{array}{c}10^{5} \mathrm{H} \\
(\mathrm{g} / \mathrm{sec}) \\
\end{array}$} & \multirow[b]{2}{*}{$\mathrm{Y}$} & \multirow{2}{*}{$\begin{array}{l}\delta t \\
(h r) \\
\end{array}$} & \multirow[b]{2}{*}{ Deviation } \\
\hline & & Expt1 & Calc & & & & & & \\
\hline \multirow[t]{4}{*}{ Chlorobenzene } & 305 & 1118 & 1162 & 156.8 & 44.5 & 7.00 & 0.288 & 0.081 & 0.001 \\
\hline & 254 & 1239 & 1327 & 155.5 & 48.7 & 3.46 & 0.562 & 0.100 & 0.006 \\
\hline & 203 & 1481 & 1545 & 153.7 & 54.3 & 1.46 & 1.230 & 0.652 & 0.008 \\
\hline & 178 & 1607 & 1682 & 152.6 & 57.8 & 0.48 & 1.639 & 0.044 & 0.039 \\
\hline \multirow[t]{2}{*}{ 1-Chloropropane } & 305 & 1039 & 982 & 158.2 & 39.8 & 11.57 & 0.198 & -0.039 & 0.014 \\
\hline & 254 & 1057 & 1132 & 157.0 & 43.7 & 5.98 & 0.434 & 0.260 & 0.004 \\
\hline Ethyl bromide & 305 & 907 & 952 & 158.5 & 39.0 & 24.97 & 0.087 & 0.072 & 0.001 \\
\hline Carbon disulfide & 305 & 1245 & 1361 & 155.2 & 49.4 & 19.94 & 0.179 & 0.056 & 0.011 \\
\hline
\end{tabular}

between calculated and observed net heat flows. The results, which are reported in Table IV-4, are relatively imprecise. Fortunately, the sought-after wall temperatures are relatively insensitive to $h_{w}$.

Column coefficients for each experimental condition were calculated from theory by the usual integration procedure based on tables of physical properties compiled previously [2]. Isotopic thermal diffusion factors used in the calculations are given in Table IV-5. The value for chlorobenzene was back-calculated from the experimental $\mathrm{H}$ at $254 \mu \mathrm{m}$. The other values were taken from Reference 2 .

The theoretical coefficients are given in Table IV-6 along with the corresponding experimentally derived values. Figures IV-3, -4 , and -5 are plots of results for the chlorobenzene series as a function of a, the hot-to-cold wall spacing.

On the basis of these experiments, the performance of the new column appears to be highly satisfactory down to a spacing
Table IV-4 - HEAT TRANSFER COEFFICIENTS AT 'THE COOLANT-COLUMN INTERFACE

$\begin{array}{cc}\begin{array}{c}\text { Water flow } \\ \text { liters/min) }\end{array} & \frac{\left(\mathrm{W} / \mathrm{cm}^{2} /{ }^{\circ} \mathrm{C}\right)}{3.96} \\ 9.54 & 0.053 \\ 24.1 & 0.065 \\ 30.0 & 0.065 \\ & 0.125\end{array}$

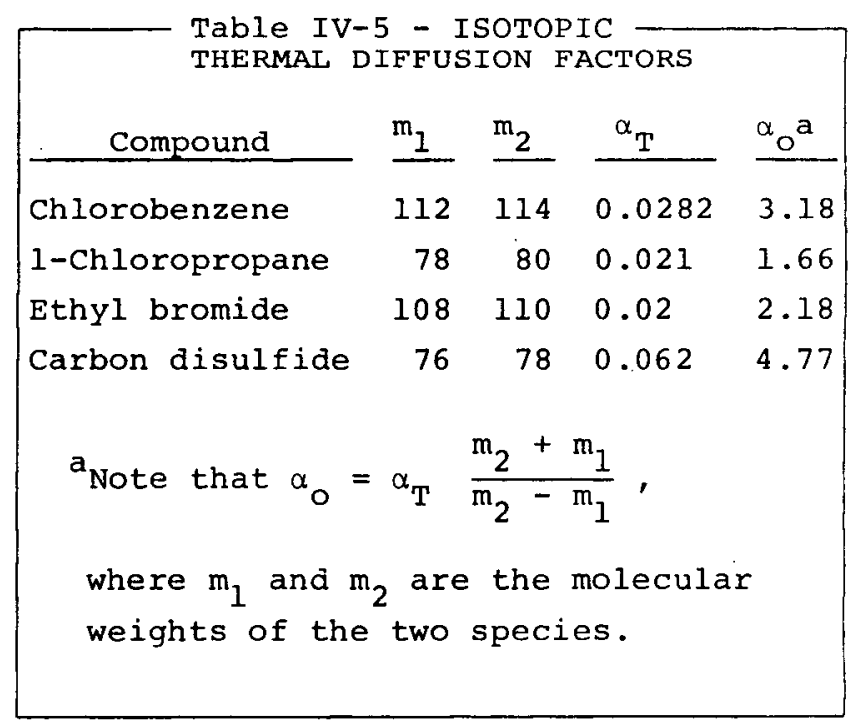




\begin{tabular}{|c|c|c|c|c|c|c|c|}
\hline \multirow[b]{2}{*}{ Compound } & \multicolumn{3}{|c|}{$\begin{array}{l}\text { DIFFUSION EXPERIMENTAL } \\
\begin{array}{l}10^{5} \mathrm{H} \\
a \quad(\mathrm{~g} / \mathrm{sec}) \\
\end{array}\end{array}$} & \multicolumn{2}{|c|}{ RESULTS WITH THEORY } & \multicolumn{2}{|c|}{$\ln \mathrm{q}_{\mathrm{E}}$} \\
\hline & $(\mu \mathrm{m})$ & Expt1 & Theory & Expt1 & Theory & Expt1 & Theory \\
\hline \multirow[t]{4}{*}{ Chlorobenzene } & 305 & 7.00 & 6.53 & 0.01107 & 0.00994 & 0.288 & 0.299 \\
\hline & 254 & 3.46 & $3.46^{\mathrm{a}}$ & 0.00280 & 0.00255 & 0.562 & 0.616 \\
\hline & 203 & 1.457 & 1.564 & $5.4 \times 10^{-4}$ & $4.81 \times 10^{-4}$ & 1.230 & 1.483 \\
\hline & 178 & 0.479 & 0.963 & $1.33 \times 10^{-4}$ & $1.77 \times 10^{-4}$ & 1.639 & 2.478 \\
\hline \multirow[t]{2}{*}{ 1-Chloropropane } & 305 & 11.57 & 11.88 & 0.0266 & 0.0341 & 0.198 & 0.159 \\
\hline & 254 & 5.98 & 6.39 & 0.00628 & 0.00890 & 0.434 & 0.327 \\
\hline Ethyl bromide & 305 & 19.2 & 28.1 & 0.100 & 0.120 & 0.087 & 0.107 \\
\hline Carbon disulfide & 305 & 39.9 & 36.7 & 0.0508 & 0.0425 & 0.357 & 0.393 \\
\hline \multicolumn{8}{|c|}{$\begin{array}{l}{ }_{\alpha_{T}} \text { was chosen to force agreement with the experimental value of } H \text { for this } \\
\text { point. }\end{array}$} \\
\hline
\end{tabular}

of $200 \mu \mathrm{m}$. The equilibrium separation at $178 \mu \mathrm{m}$ was found to be higher than the corresponding value at $203 \mu \mathrm{m}$. This is the first time that such a result has been achieved. In almost all previous work the maximum separation was reached at spacings equal to or larger than 200 $\mu \mathrm{m}$, and the rapid onset of nonideal parasitic effects at lower spacings led to separations significantly smaller than those predicted theoretically. There seems, however, to be some impediment to the thermogravitational circulation in the $178 \mu \mathrm{m}$ configuration. Both $\mathrm{H}$ and $\mathrm{K}$ are low relative to theory. Normally, parasitic effects would lead to a remixing effect larger than that predicted. The remixing coefficient is proportional to the square of the mass circulation rate in the column; hence, the conclusion is that circulation is restricted.

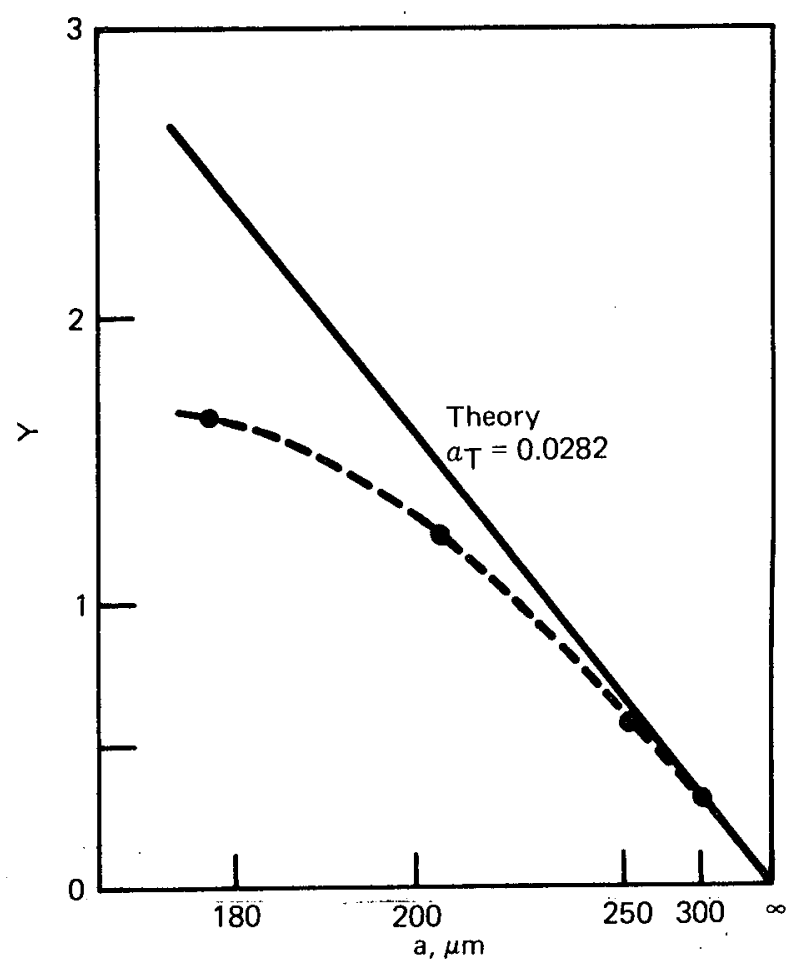

FIGURE IV-3 - Equilibrium separation factor for chlorobenzene in the new research column. The abscissa is linear in $1 / a^{4}$. 


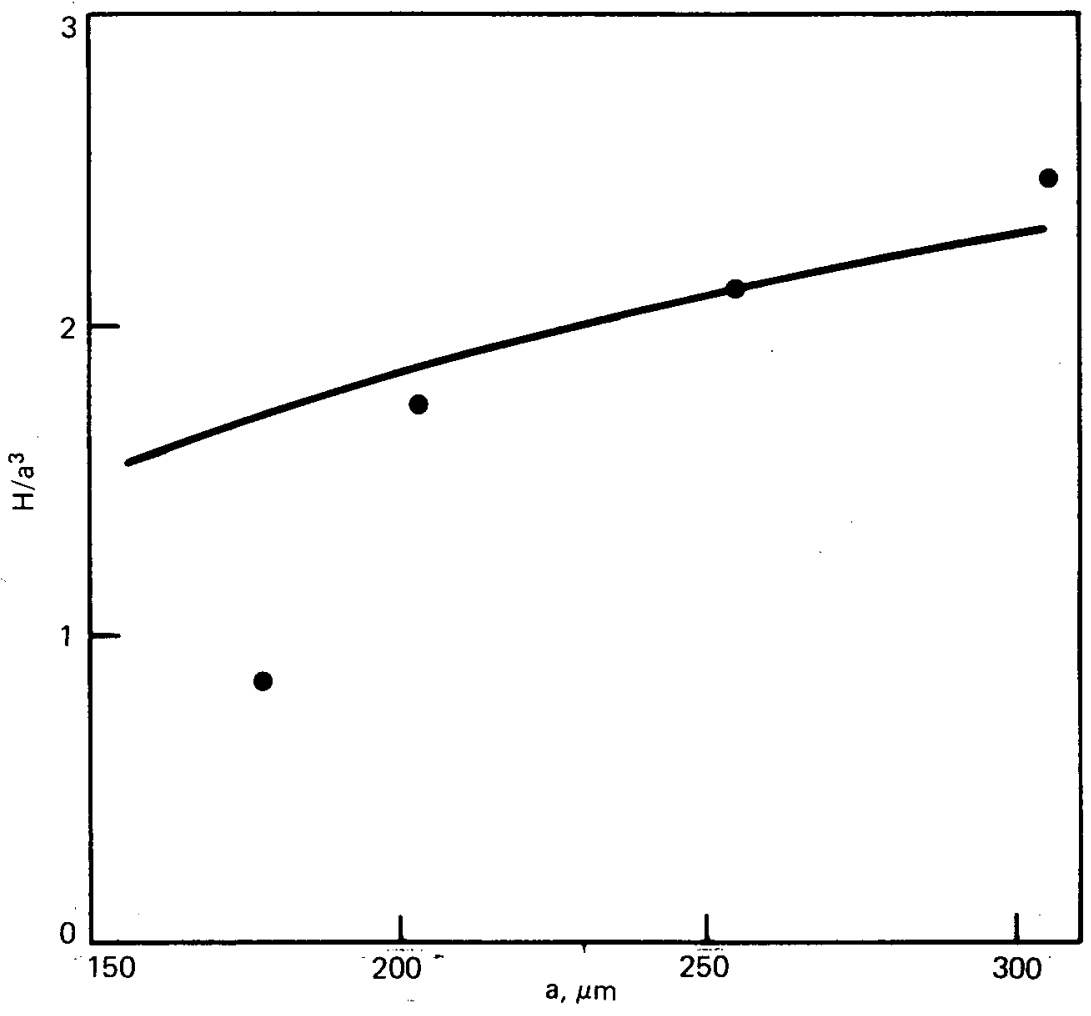

FIGURE IV-4 - Initial transport coefficient for chlorobenzene liquid thermal diffusion experiments. The solid line is calculated from theory for $\alpha_{t}=0.0282$.

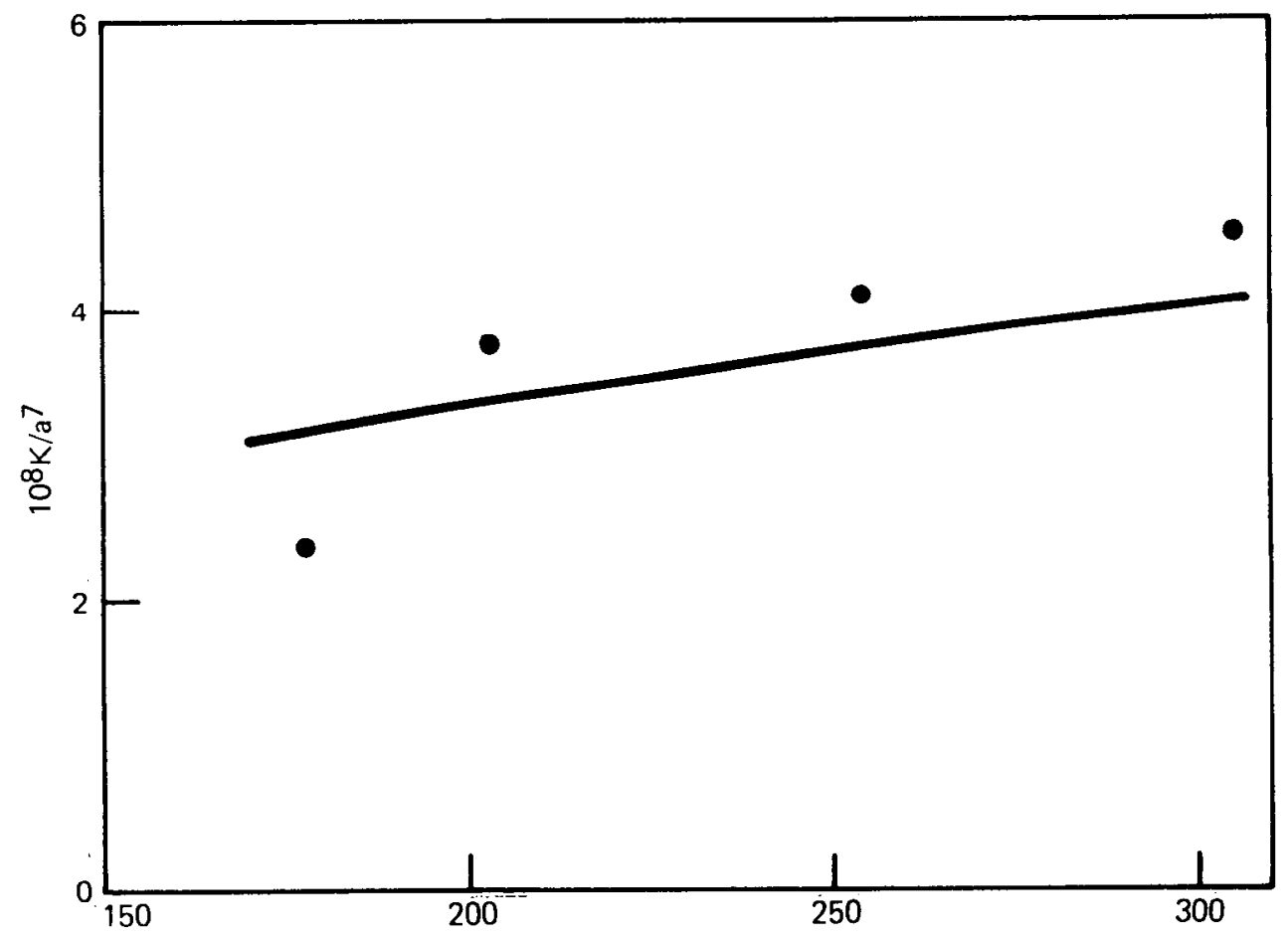

a, $\mu \mathrm{m}$

FIGURE IV-5 - Remixing coefficient for chlorobenzene liquid thermal diffusion experiments. The solid line is calculated from theory. 


\section{Calcium isotope separation}

\author{
W. M. Rutherford and K. W. Laughlin
}

Liquid phase thermal diffusion is being investigated as a means of separating calcium isotopes. Thermal diffusion has been successfully applied to the separation of practical quantities of isotopes of elements having simple liquid compounds. Calcium, however, does not form a compound which is liquid in the practical range of temperatures; therefore, it is necessary to work with solutions of calcium salts in suitable solvents. The solutions cannot be processed in a straightforward way because the thermal diffusion separation of solute and solvent is much larger than the expected isotope effect.

The initial phases of this work have been directed toward 1) the construction and testing of an apparatus designed to offset the solute-solvent separation effect by controlled injection and 2 ) the removal of pure solvent at the ends of the separation column. It was shown theoretically that this could be accomplished without affecting the isotopic separation if the solvent injection rate were chosen such that

$$
\sigma=\mathrm{Hw}_{1}
$$

where $\sigma$ is the injection rate, $H$ is the initial transport coefficient for the solvent solute pair, and $w_{1}$ is the solvent mass fraction.

We have previously reported the evaluation of solute-solvent separation parameters as functions of concentration for the
$\mathrm{Ca}\left(\mathrm{NO}_{3}\right)_{2}$ - water system, and have described the first experiment aimed at establishing a uniform solute concentration in the separation system [3]. A large, initially undetected leak diminished the significance of the experiment, although a slight separation of the isotopes was found in one set of samples.

Several additional experiments have now been completed, and a new, shorter column has been constructed for evaluation of the isotope effect without solvent injection. In addition, materials compatibility tests were run on aqueous solutions of calcium salts which might be used in place of $\mathrm{Ca}\left(\mathrm{NO}_{3}\right)_{2}$.

The experiments involving solvent injection were conducted with the apparatus described in the previous report. The column was a standard 304 stainless steel unit, $72 \mathrm{~cm}$ long, $2.5 \mathrm{~cm}$ annular diameter, with a hot-to-cold wall spacing of $254 \mu \mathrm{m}$. The system was filled for the second experiment with a solution containing 20 wt $\% \mathrm{Ca}\left(\mathrm{NO}_{3}\right)_{2}$ in water. At this concentration, we have found that the initial transport coefficient for the solute-solvent separation is:

$$
\mathrm{H}=7.25 \times 10^{-4} \mathrm{~g} / \mathrm{sec}
$$

Thus, according to Equation 1 we require a solvent injection rate of $2.088 \mathrm{~g} / \mathrm{hr}$. The closest pump setting, $2.42 \mathrm{ml} / \mathrm{hr}$, was chosen for the experiment.

Figure IV-6 is a plot of the $\mathrm{Ca}\left(\mathrm{NO}_{3}\right)_{2} \mathrm{con-}$ centrations at the top and bottom of the system as functions of time during the 


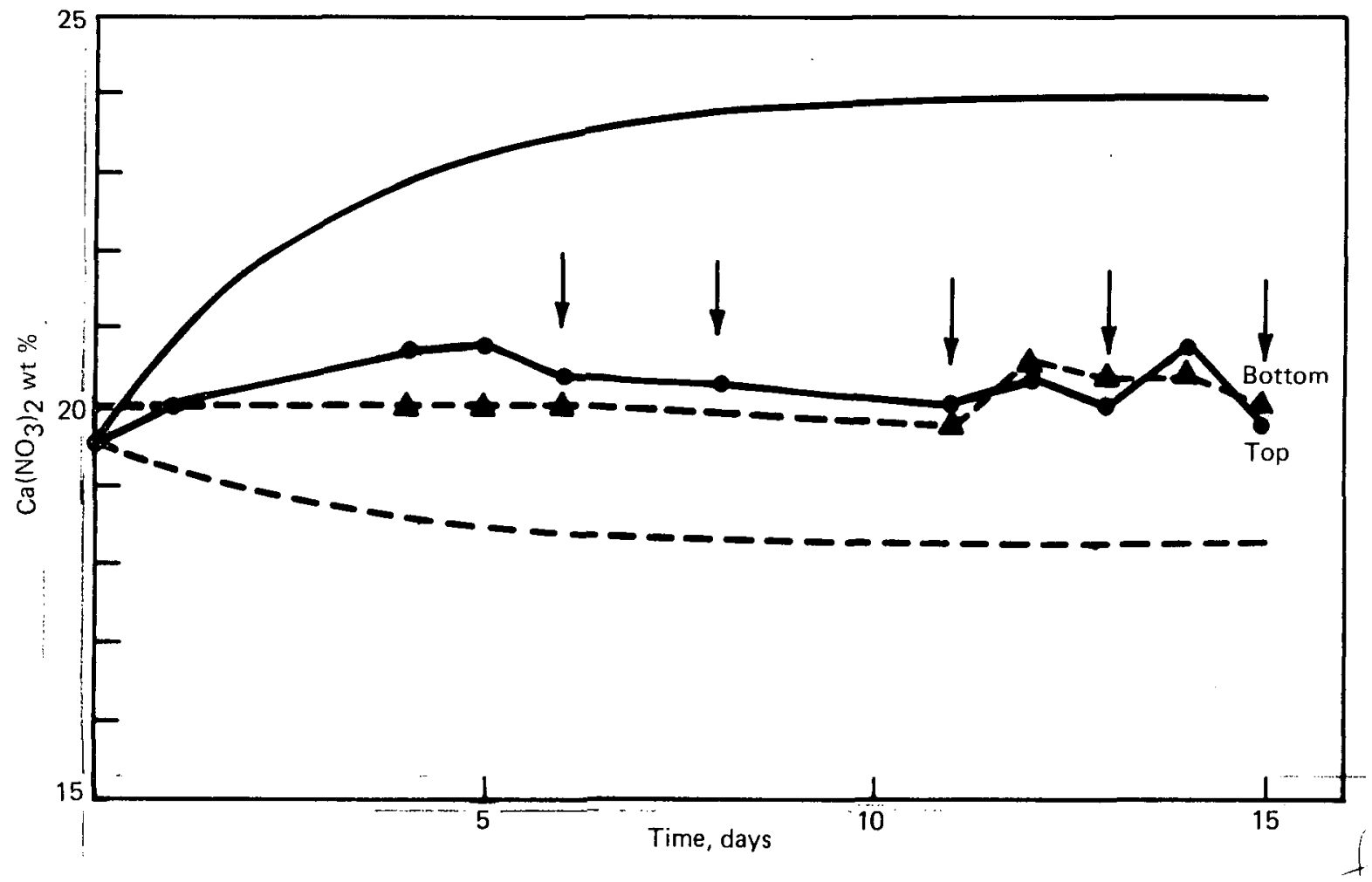

FIGURE IV-6 - Solute concentrations during Experiment 2. The arrows indicate when samples were taken for isotopic ratio measurements. The smooth curves are calculated from theory.

experiment. The system was maintained in a relatively stable condition for 15 days, and five sets of samples were taken for isotope ratio determinations, starting on the sixth day.

Results of the isotopic ratio determinations on the five samples are given for the ${ }^{40} \mathrm{Ca}-{ }^{48} \mathrm{Ca}$ pair in Table IV-7. Three of the samples show no separation of the isotopes; however, samples taken on day 11 and day 15 had separations well in excess of the estimated standard deviation in the separation factor. The separation factor is defined by

$$
q=\frac{\left(w_{48} / w_{40}\right)_{B}}{\left(w_{48} / w_{40}\right)_{T}}
$$

where $w$ is the mass fraction, and the subscripts $T$ and $B$ refer to the top and bottom of the system, respectively. The estimated standard deviation in $\mathrm{q}$ is \pm 0.01 . The separation on day 11 amounted to a shift of approximately $5 \%$ in the isotopic abundance of ${ }^{48} \mathrm{Ca}$; however, the system was clearly unstable and on day 13 the separation factor had dropped to unity within the precision of the measurement.

The third and fourth experiments were run at much higher concentrations approaching the solubility limit of $\mathrm{Ca}\left(\mathrm{NO}_{3}\right)_{2}$ at room temperature. There is some evidence for a larger isotopic effect at higher concentrations. Panson, for instance, found no separation of lithium isotopes in $0.5 \mathrm{M}$ $\mathrm{LiNO}_{3}$, but at $5 \underline{\mathrm{M}} \mathrm{LiNO}_{3}$ observed separation factors of up to 1.22 [4].

Experiment 3 was run at 38 wt $8 \mathrm{Ca}\left(\mathrm{NO}_{3}\right)_{2}$. Solute-solvent separation data obtained 


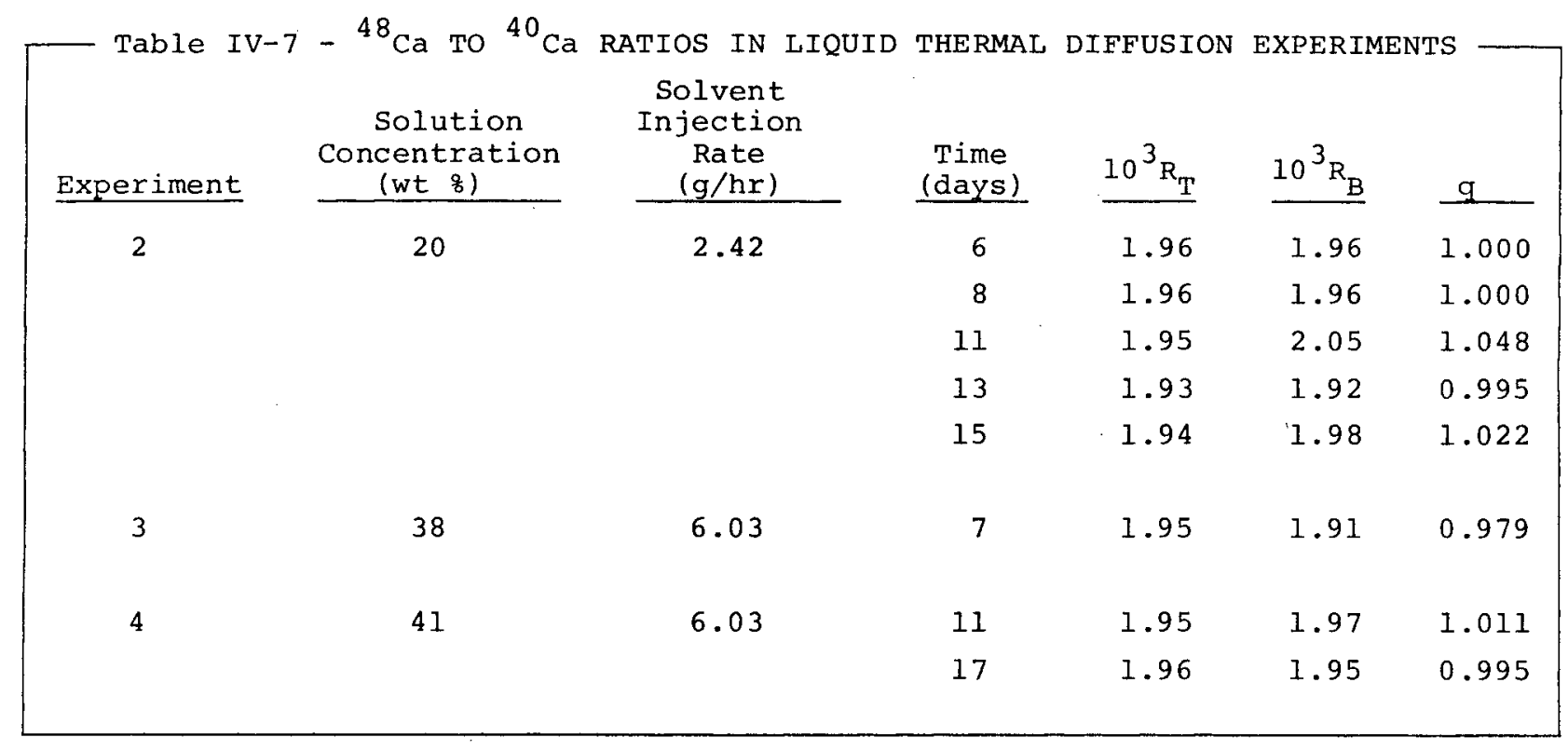

previously do not cover this concentration range. Since $\mathrm{H}$ decreases with concentration we can say only that

$$
\mathrm{H}<5.7 \times 10^{-4}
$$

where $5.7 \times 10^{-4}$ is the value at $25 \mathrm{wt} \%$, and the associated solvent injection rate, $\sigma$, required according to Equation 1 , is $o<1.27 \mathrm{~g} / \mathrm{hr}$.

The solvent injection rate for the experiment was selected at a much higher value, $6.03 \mathrm{~g} / \mathrm{hr}$, to determine whether the predicted inversion would occur in the solutesolvent concentration profile $\left(\mathrm{Ca}\left(\mathrm{NO}_{3}\right)_{2}\right.$ more concentrated at the top).

Solute concentrations during the experiment, which are plotted in Figure IV-7, do not show the expected concentration inversion. Samples were taken for isotopic ratio determination on day 7 . The results, reported in Table IV-7, show a negative separation slightly greater than twice the standard deviations.

Experiment 4, the results of which are plotted in Figure IV-8, was essentially

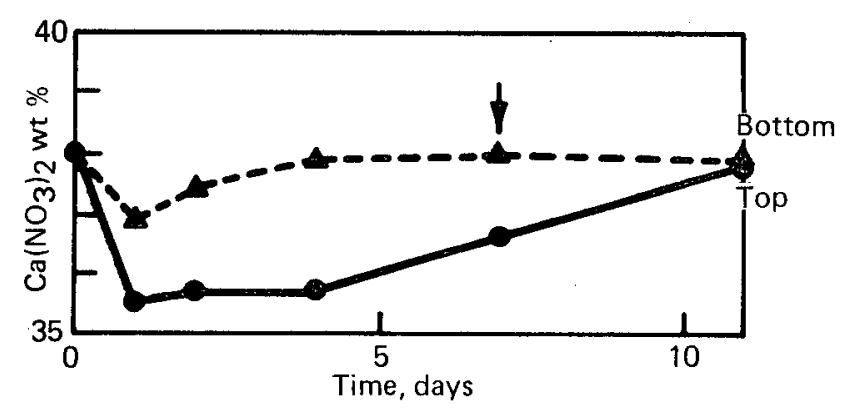

FIGURE IV-7 - Solute concentrations during Experiment 3 . The arrow indicates when samples were taken for isotopic ratio measurements.

the same but with a slightly higher initial concentration. Again, the expected concentration inversion was not observed. Samples taken on days 11 and 17 of the experiment did not show significant isotopic separation (see Table (V-7).

At this point, it appeard desirable to confirm the existence of an isotope effect for calcium without the complication of solvent injection. Exploratory calculations indicated that this could be done with a column approximately half as long as the first column. At this length the solute-solvent separation is much smaller, 


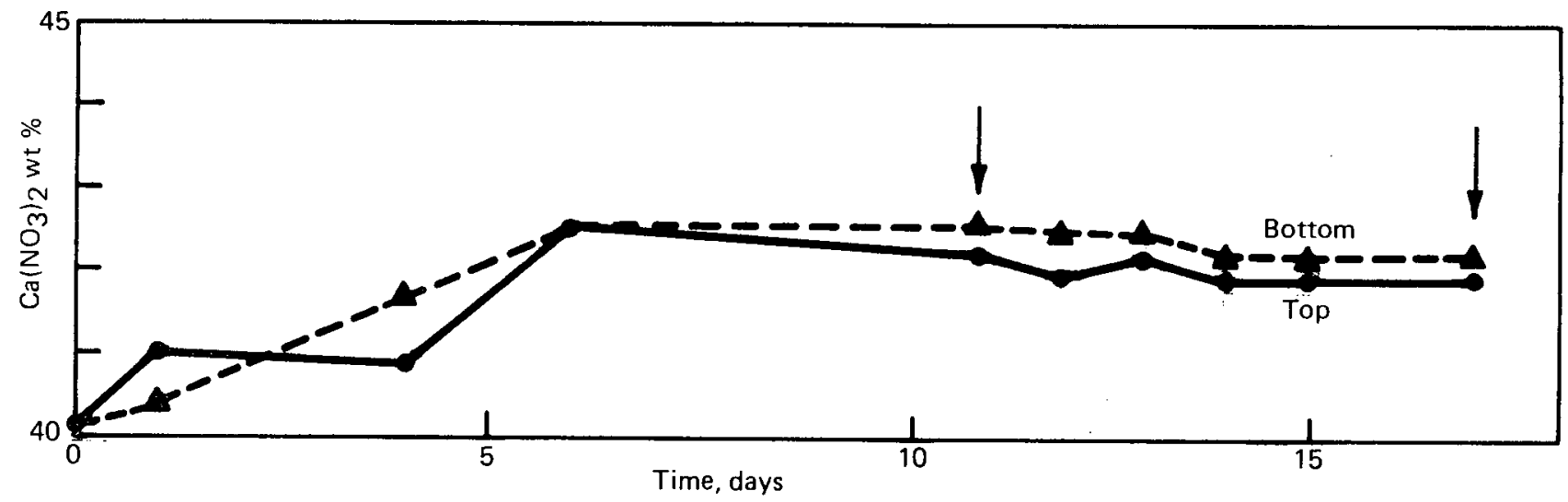

FIGURE IV-8 - Solute concentrations during Experiment 4. The arrows indicate when samples were taken for isotopic ratio measurement.

and it should be possible to stay below the solubility limit at the bottom of the column, yet retain enough solute at the top for isotopic ratio determination. The isotopic separation, of course, would also be significantly smaller in the shorter column.

A second column was constructed with a design identical to the first, but with a length of $36.5 \mathrm{~cm}$ instead of $72.1 \mathrm{~cm}$. The column was filled with a solution that was adjusted to yield, at equilibrium, $0.5 \% \mathrm{Ca}\left(\mathrm{NO}_{3}\right)_{2}$ at the top and $38 \% \mathrm{Ca}\left(\mathrm{NO}_{3}\right)_{2}$ at the bottom. Two sets of samples were removed for isotopic ratio determination after sufficient time had elapsed to reach a steady state condition. The results, which are given in Table IV-8 and Figure IV-9 show a significant separation of the isotopes. The isotopic concentration of ${ }^{48} \mathrm{Ca}$ in the top sample is depleted by 5 to $6 \%$ relative to natural abundance. As expected from material balance considerations, the bottom sample is close to natural abundance. The natural logarithm of the separation factor is essentially linear with mass, as one would predict from theory.
This work demonstrates that there is a significant thermal diffusion separation of calcium salts in solution. The failure to find consistent separations in the solvent injection experiments is probably the result of convective instability in the experimental column. All four experiments were run under conditions which would tend to create an unstable density gradient with density increasing in the vertical direction. It is known that such gradients can destroy the separation in the column by rapid convective mixing of the column contents.

The obvious next step is to repeat the experiments under conditions such that a stable density gradient is maintained at all times. This will require: 1) solvent injection rates lower than those specified by Equation 1; 2) delayed initiation of solvent injection to allow time for formation of a stable gradient; and 3) rapid circulation of fluids through the ends of the column to avoid concentration and density differences between inflow and outflow streams. 


\begin{tabular}{|c|c|c|c|c|c|}
\hline \multirow[b]{2}{*}{ Sample } & \multicolumn{5}{|c|}{$\begin{array}{l}\text { FOR SHORT COLUMN EXPERIMENT WITHOUT } \\
\text { SOLVENT INJECTION }\end{array}$} \\
\hline & ${ }^{40} \mathrm{Ca}$ & ${ }^{42} \mathrm{Ca}$ & Wh $\%$ & ${ }^{44} \mathrm{Ca}$ & ${ }^{48} \mathrm{Ca}$ \\
\hline 1-Tор & 96.92 & 0.639 & 0.137 & 2.13 & 0.180 \\
\hline 1-Bottom & 96.84 & 0.647 & 0.140 & 2.18 & 0.190 \\
\hline 2-Top & 96.91 & 0.639 & 0.138 & 2.14 & 0.181 \\
\hline 2-Bottom & 96.84 & 0.647 & 0.140 & 2.18 & 0.190 \\
\hline $\begin{array}{l}\text { Feed } \\
\text { Material } \\
\text { (Natural } \\
\text { Abundance) }\end{array}$ & 96.86 & 0.643 & 0.140 & 2.17 & 0.188 \\
\hline
\end{tabular}

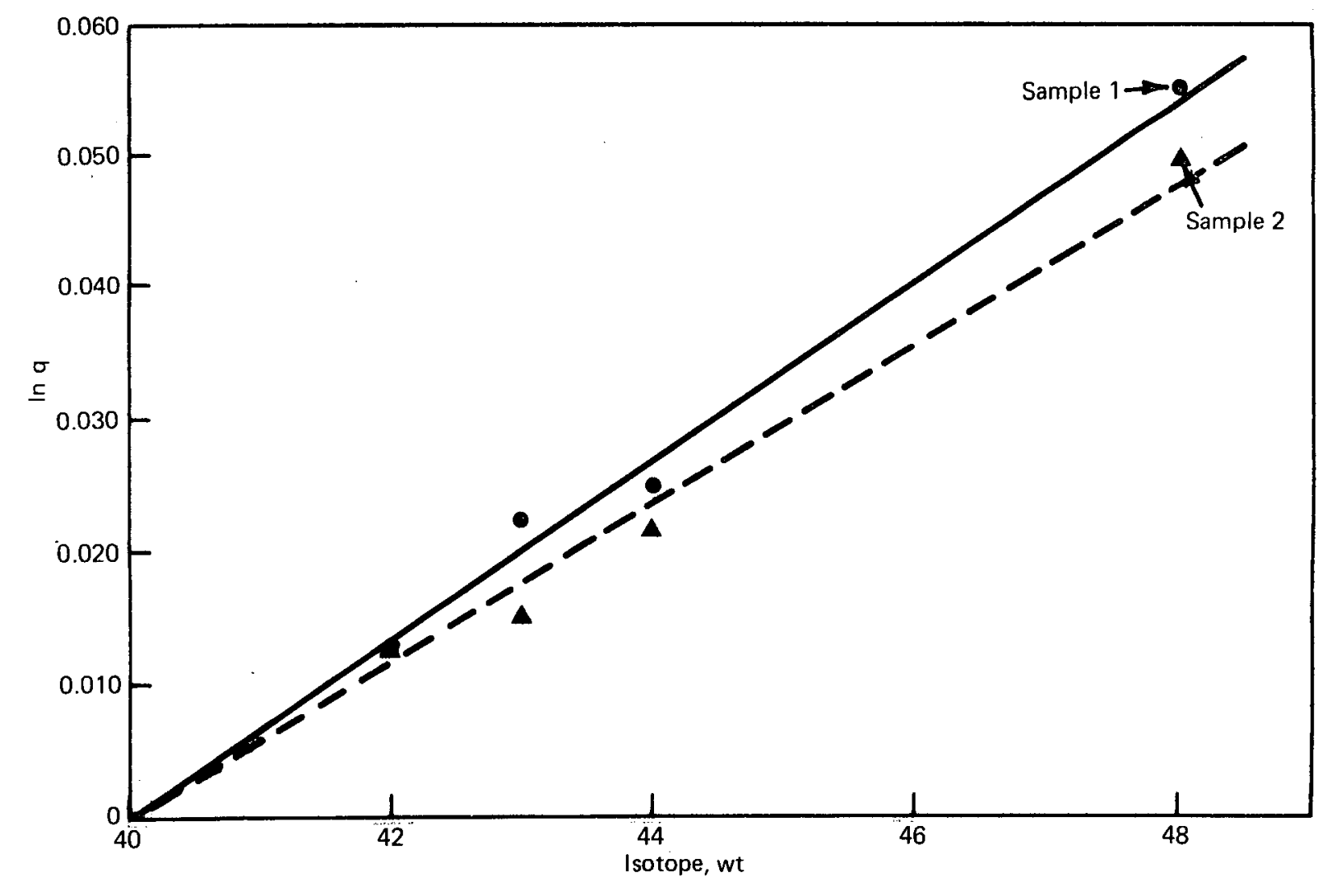

FIGURE IV-9 - Separation relative to ${ }^{40} \mathrm{Ca}$ in a $36.5 \mu \mathrm{m}$ thermal diffusion column. 
VERIFICATION OF ANALYTICAL PROCEDURE

Procedures used in preparing and analyzing isotopic ratio samples were verified by analysis of a synthetic calcium isotope mixture.

A calcium nitrate solution of natural isotopic abundance was spiked with a small amount of highly enriched ${ }^{44} \mathrm{Ca}$ purchased from oak Ridge. The sample was thereafter processed in the same way as the other samples. Results of the analysis are compared in Table IV-9 with results calculated from the combination of 1) literature values for the isotopic abundances, 2) the Oak Ridge ${ }^{44} \mathrm{Ca}$ assay, and 3) the measured dilution ratio. The agreement is considered satisfactory in relation to the probable error in experimental measurement of the dilution ratio.

\begin{tabular}{|crc|}
\hline Table IV-9 - ISOTOPIC & ANALYSIS OF A \\
SPIKED CALCIUM SAMPIE & $\begin{array}{c}\text { Expt } 1 \\
(\mathrm{at.8})\end{array}$ & $\begin{array}{c}\text { Calc } \\
(\mathrm{at.} 8)\end{array}$ \\
$\mathrm{Ca}-40$ & 95.819 & 96.04 \\
$\mathrm{Ca}-42$ & 0.626 & 0.62 \\
$\mathrm{Ca}-43$ & 0.130 & 0.13 \\
$\mathrm{Ca}-44$ & 3.258 & 3.07 \\
$\mathrm{Ca}-48$ & 0.166 & 0.17 \\
\hline
\end{tabular}

\section{ALTERNATIVE CHEMICAL SYSTEMS}

Systems other than $\mathrm{Ca}\left(\mathrm{NO}_{3}\right)_{2}{ }^{-\mathrm{H}_{2} \mathrm{O} \text { may have }}$ better characteristics for use in a calcium isotope separation system. Parameters which are important are solubility, stability, and compatibility with materials suitable for constructing thermal diffusion columns. Two experiments were performed in the most recent work on the compatibility of calcium salts and selected metals. One involved $\mathrm{CaCl}_{2}$ and titanium and the other involved $\mathrm{Ca}(\mathrm{SCN})_{2}$ and 304 stainless steel, our standard column material.

Titanium was chosen because of its known resistance to chloride solutions. Titanium and aqueous $\mathrm{CaCl}_{2}$ solution compatibility near column service temperature was unclear; thus, a small mock-up column made of titanium was constructed. The column was filled with a 25 wt $8 \mathrm{CaCl}_{2}$ solution and pressurized to 125 psig. The column was then subjected to a temperature of $180^{\circ} \mathrm{C}$ for six weeks.

The test column had no cooling jacket so the column was at a higher temperature than would be encountered in normal service. After the test the column was cut apart and examined under magnification. No apparent corrosion took place; therefore, a titanium column seems to offer a solution to the stress corrosion cracking problem that occurs with aqueous halide salt solutions and 304 stainless steel.

Work involving lithium by Panson [4] and by Korsching and Wirtz [5] suggests that higher concentrations of a salt in aqueous solution produce larger isotopic separations than do lower concentrations. The aqueous phase solubility of $\mathrm{Ca}(\mathrm{SCN})_{2}$ is quite high; therefore, an aqueous solution of $\mathrm{Ca}(\mathrm{SCN})_{2}$ was evaluated in corrosion tests. A small bar of 304 stainless steel was weighed and placed in a boiling, 60 wt 8 solution of $\mathrm{Ca}(\mathrm{SCN})_{2}$ for one week. After completion of the test the bar was re-weighed. It showed no significant weight loss or surface effects; however, the $\mathrm{Ca}(\mathrm{SCN})_{2}$ apparently decomposed and thus seems too unstable for the calcium work. 


\section{Molecular beam scattering}

\author{
R. W. York and W. L. Taylor
}

HELIUM-ARGON TOTAL SCATTERING CROSS SECTIONS

The helium-argon series of total scattering cross section experiments has been concluded successfully with a total of 58 experiments. This series covers the relative 'velocity range from $0.8-2.0 \mathrm{x}$ $10^{5} \mathrm{~cm} / \mathrm{sec}$. Included were eight experiments performed with the source and target species inverted to permit an indication of any unknown systematic errors which might affect the accuracy of the data. Reduction of the experimental data and application of resolution and velocity distribution corrections will be undertaken at a later date.

NEON-ARGON TOTAL SCATTERING CROSS SECTIONS

The neon-argon experimental cross sections reported previously [6] were corrected for the apparatus resolution and converted to the relative center-of-mass system for comparison with theoretical values. A new computer program was written to evaluate the resolution corrections using an improved numerical integration method for the calculations. The various cross sections of interest are given in Table IV-10 with the last three columns representing the results of the present data analysis. The resolution corrections, $\Delta Q$, are no more than a few percent for a neon beam on an argon target, reflecting the high resolution of the apparatus. The "effective cross section" is given by

$$
Q_{\text {eff }}=Q_{\text {exp }}+\Delta Q
$$

In order to account for the fact that there is no singular relative velocity for the collision partners, the appropriate Berkling function [7], F, must be applied to the effective cross section. $F$ is a correction factor which is a function of the quotient $x=v_{b} / v_{t}$, where $v_{b}$ is the beam velocity and $v_{t}$ is the most probable target speed. In the present experiments the beam is assumed to be monochromatic and the target is assumed to possess a Maxwellian velocity distribution. Hence

$$
Q\left(v_{b}\right)=Q_{e f f} / F a_{0}(6, x)
$$

where $F a_{0}(6, X)$ is the appropriate tabulated function in the reference. In order to compare it to theoretically calculated cross sections, it is necessary to transform the $Q\left(v_{b}\right)$ to the relative center-tomass velocity employed in the theory. In the first approximation

$$
Q\left(v_{r}\right)=Q\left(v_{b}\right)\left(v_{b} / v_{r}\right)^{\frac{2}{s-1}}
$$

where $v_{r}$ is the relative velocity, $s=6$ is the inverse power dependence of the long range attractive portion of the potential, e.g., $V(r)=-C(\sigma / r)^{S} . Q\left(\nu_{r}\right)$, where $v_{x}=\left(v_{b}^{2}+v_{t}{ }^{2}\right)^{\frac{1}{2}}$, is given in the last column of the table. The data are plotted along with theoretical cross sections for five intermolecular potentials in Figure IV-10. The solid circles represent the present data with beam source conditions adjusted so that dimerization, or "clustering," of neon atoms does not occur in the nozzle-skimmer region of the beam. The open circles represent experiments where source pressure was increased to a point at which dimerization theoretically should occur. This appears to be the case as the cross sections are longer in all cases. The open triangle represents an argon beam and neon target gas. This 


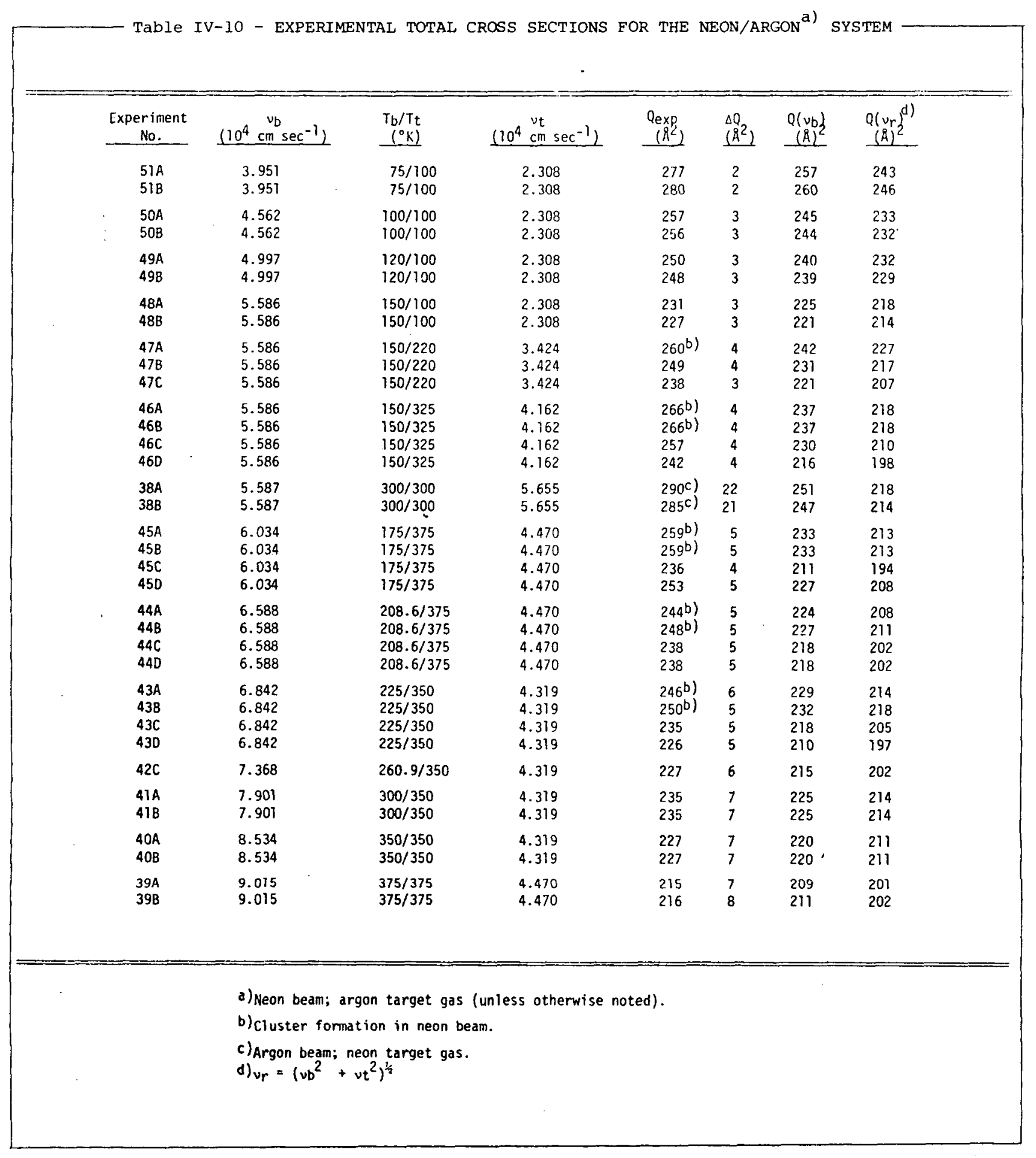




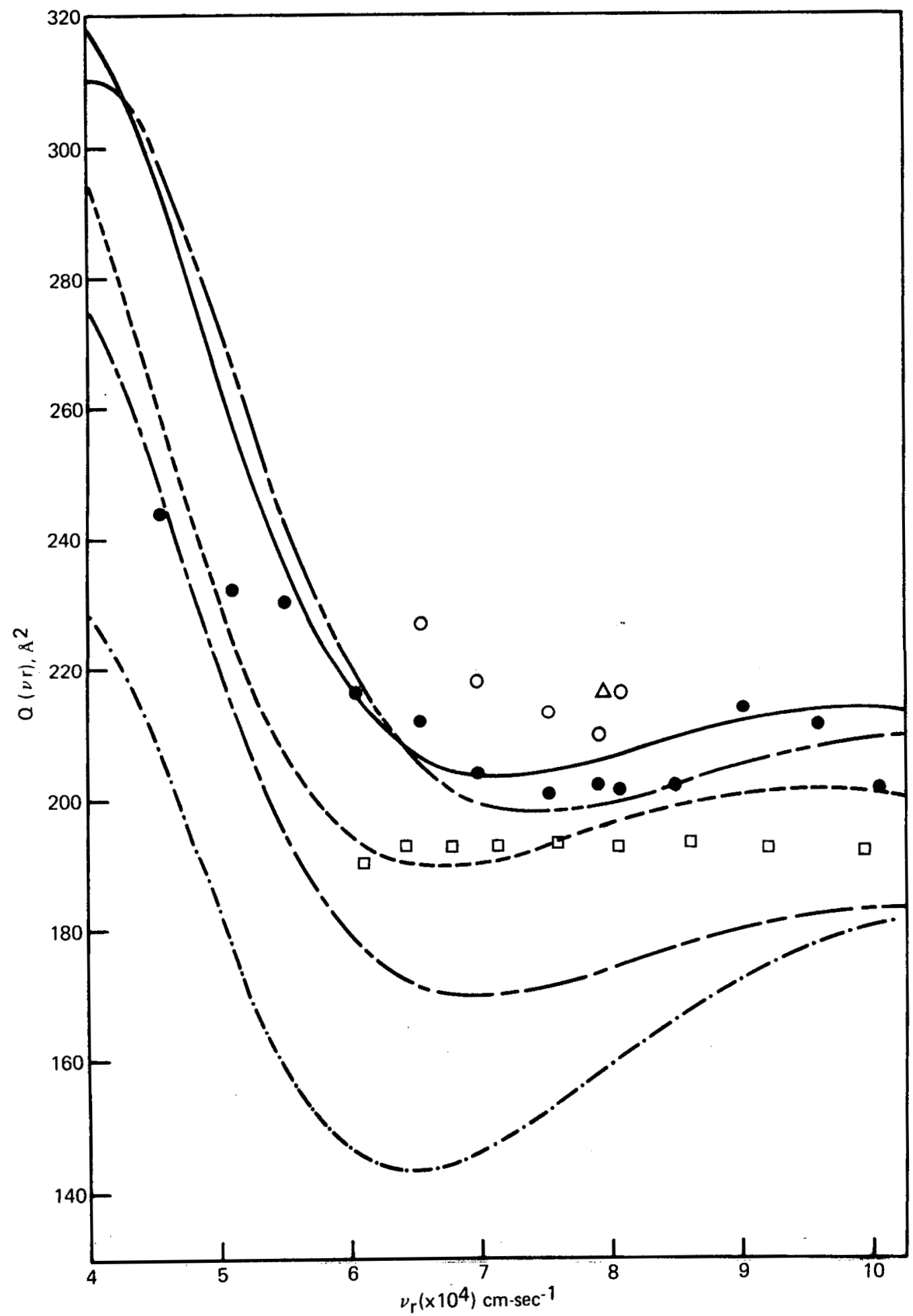

FIGURE IV-10 - Neon-argon total cross sections. The experimental points are: - Neon beam, argon target, no neon dimerization in beam; $O$, neon beam, argon target, theoretical possibility of significant neon dimerization in beam; $\Delta$, argon beam, neon target; $\square$, Shinn (Ref. 8). The theoretical curves are: -, Lennard-Jones $(12-6)$ potential with parameters by Hogervorst (Ref. 10); -.., Exp-6 potential with parameters by Hogervorst (Ref. 10); ---, Exp-6 potential with parameters by Mason and Rice (Ref. 11); --, ESMSV potential by Ng, et al (Ref. 12); and -.., Dymond-Alder potential with parameters by Lin and Robinson $(\operatorname{Ref} .13)$. 
"inverted experiment" is about $78 \mathrm{high}$ and could be an indication of the magnitude of possible systematic errors in the experiments. The open squares are earlier measurements [8] made at the University of Virginia. In the mid-range of velocities the independent measurements (solid circles and open squares) agree to within $5 \%$. The University of Virginia data do not rise as one would expect, although, as Shinn pointed out, the lowest points are the least reliable.

Theoretical. calculations were made using the WKB calculated phase shifts to evaluate the cross sections. First the validity of the calculation was checked according to the criteria of Munn et al [9]. It was found that our lowest relative energy was approximately $3-1 / 2$ times the minimum allowed so that the WKB approximation should be reasonably accurate for the phase shifts. It can be noted in the figure that all the potentials considered rise more rapidly at low energies relative to the experimental data, so further consideration should be given to the numerical procedures used to evaluate the phase shifts. On the other hand, of the potentials investigated, which are shown in Figure IV-ll, only the ESMSV potential includes a $-C_{2}(\sigma / r)^{8}$ term in the long range attraction and this is known to have a significant effect at low energies. On the basis of the two sets of data one certainly could not choose a potential that is entirely satisfactory and at this point only a few general observations can be made. The absolute magnitude of the data at higher velocities as well as the location of the inflection, or "glory," appears to be predicted more accurately by either the Exp-6 or the I.J. potential. on the other hand, as noted above, none of the potentials exhibits low energy behavior in agreement with the data. Because the total cross section is sensitive to the value of $\sigma$ in the potential, one could infer from the inset in Figure IV-11 that the large values are preferable. Further analyses of the effects of the potential are necessary and are in progress.

DETECTION SYSTEM

The rotatable, triply-pumped detector housing, which was previously described [6], has been received from the fabricator and has undergone initial leak testing satisfactorily. Thus far, no leaks have been found although some irregularities in fabbrication necessitated the return of the housing to the vendor for rework. The rework has now been completed and the housing is ready for final delivery to Mound. The complete system will be installed in the beam chamber during the next reporting period.

\section{VELOCITY SELECTION}

The rotor for the velocity selector has been rebalanced and realigned. It now runs smoothly without vibration to $30,000 \mathrm{rpm}$. This represents a major improvement over previous performance. A new, all stainless steel diffusion pump with increased pumping speed was added to the bell jar vacuum system to permit higher vacuum conditions, thus promoting a higher signal-to-noise ratio.

\section{Mutual diffusion}

\section{Cain, K. D. Westrick and W. L. Taylor}

The study of the diffusion coefficients of krypton-noble gas systems has been completed 


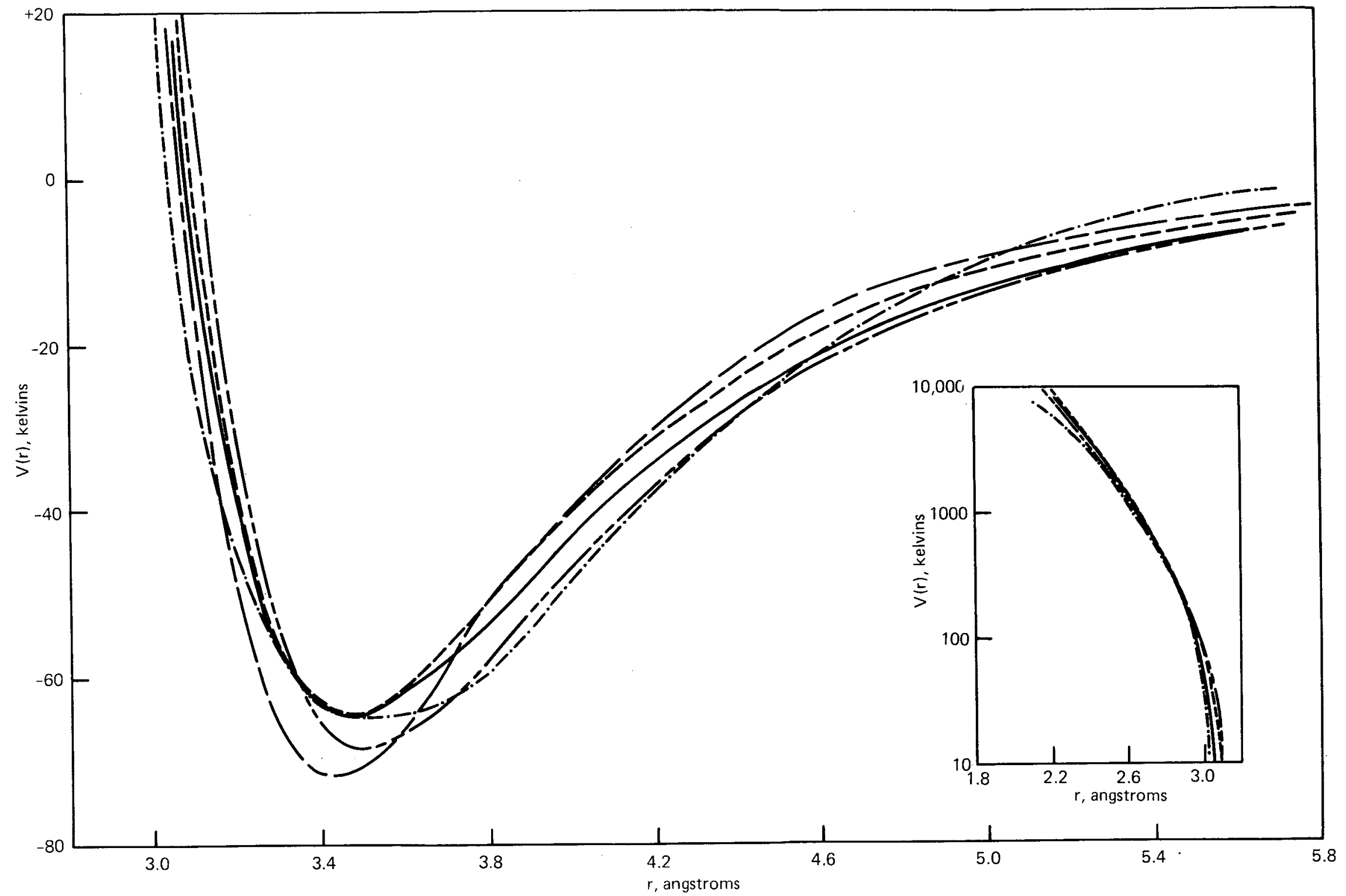

FIGURE IV-11 - Intermolecular potentials for the neon-argon system. The larger graph depicts the well and long-range attractive regions of potentials; the inset shows the repulsive regions of potentials. The curves are the same as in Figure IV-10. 
over the presently attainable temperature range--approximately 340 to $1300 \mathrm{~K}$ [14]. Attention has since shifted to the heliumneon, argon, xenon, and argon-xenon systems. Table IV-11 shows the temperature ranges over which diffusion coefficients of binary mixtures of the noble gases have been measured at Mound. As can be seen, the mixtures of current interest are the only remaining asymmetric systems whose temperature dependence has not been well characterized. Helium-argon has been studied over a very brief temperature range while helium-neon has been investigated only below room temperature [15]; the other two systems mentioned have not been investigated at Mound at a11.

Table IV-12 shows the experimental diffusion coefficients, $D_{12}$, measured to date for helium-argon, xenon, and argon-xenon.
The data have been adjusted to atmospheric pressure and are for systems tending toward an equimolar equilibrium concentration. Other experimental diffusion coefficient values have been obtained from the literature and adjusted (where necessary) to equilmolar composition [20]. Initial comparisons are favorable, although a detailed study has not yet been done for helium-xenon or argon-xenon. The situation with helium-argon, however, is very different.

The lone high temperature diffusion coefficient for helium-argon 1 isted in Table IV12 is a result of a request of $R$. A. Aziz of the University of Waterloo [21]. In a recent paper on the interatomic potential of the helium-argon system, Aziz [22] found that the high temperature diffusion coefficients of Hogervorst [23] could not be calculated from potentials determined Table IV-11 - TEMPERATURE RANGES (K) OF MOUND DIFFUSION DATA

\begin{tabular}{|c|c|c|c|c|c|}
\hline & $\mathrm{Xe}$ & $\mathrm{Kr}$ & Ar & $\mathrm{Ne}$ & $\mathrm{He}$ \\
\hline $\mathrm{He}$ & $---^{a}$ & $358-1194^{b}$ & $305-335^{c, a}$ & $77-364^{c}$ & $77-888^{C}$ \\
\hline $\mathrm{Ne}$ & $304-922^{d}$ & $350-1222^{b}$ & $296-1363^{e}$ & $77-1400^{f}$ & \\
\hline Ar & $---^{a}$ & $339-1195^{b}$ & ---9 & & \\
\hline $\mathrm{Kr}$ & $358-1199^{b}$ & $196-1036^{\mathrm{h}}$ & & & \\
\hline $\mathrm{Xe}$ & $\ldots-\ldots$ & & & & \\
\hline
\end{tabular}

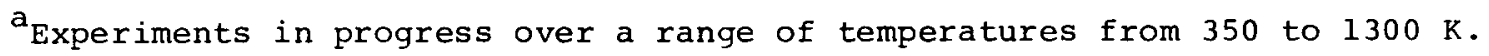

$\mathrm{b}_{\text {Ref . } 14}$

CRef. 15

$\mathrm{d}_{\text {Ref . } 16}$

efef. 17

$\mathrm{f}_{\text {Ref. } 18}$

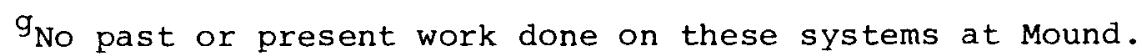

$\mathrm{h}_{\text {Ref . }} 19$ 
Table IV-12 - DIFFUSION COEFFICIENTS AT ONE ATMOSPHERE PRESSURE, EQUIMOLAR EQUILIBRIUM CONCENTRATION

\begin{tabular}{|c|c|c|c|c|c|}
\hline \multicolumn{2}{|c|}{$\mathrm{Ar}-\mathrm{Xe}$} & \multicolumn{2}{|c|}{ He-Xe } & \multicolumn{2}{|c|}{$\mathrm{He}-\overline{\mathrm{Ar}} \mathrm{r}$} \\
\hline $\begin{array}{l}\text { Temperature } \\
(\mathrm{K})\end{array}$ & $\begin{array}{r}\mathrm{D}_{12} \\
2 \\
\left(\mathrm{~cm}^{2} / \mathrm{sec}\right) \\
\end{array}$ & $\begin{array}{l}\text { Temperature } \\
(\mathrm{K})\end{array}$ & $\begin{array}{c}D_{12} \\
2 \\
\left(\mathrm{~cm}^{2} / \mathrm{sec}\right) \\
\end{array}$ & $\begin{array}{l}\text { Temperature } \\
\text { (K) }\end{array}$ & $\begin{array}{c}\mathrm{D}_{12} \\
\left(\mathrm{~cm}^{2} / \mathrm{sec}\right) \\
\end{array}$ \\
\hline 343.9 & 0.1501 & 351.1 & 0.7428 & 1307.4 & 10.049 \\
\hline 499.6 & 0.2947 & 657.9 & 2.1099 & & \\
\hline 512.8 & 0.2975 & 793.5 & 2.7656 & & \\
\hline 656.3 & 0.4766 & 941.5 & 3.8553 & & \\
\hline 822.3 & 0.7241 & 1217.2 & 5.8779 & & \\
\hline 948.0 & 0.9163 & & & & \\
\hline 1106.5 & 1.1686 & & & & \\
\hline
\end{tabular}

solely from differential cross sections. since high temperature diffusion data are often used to determine the repulsive wall of the interatomic potential, and since we had previously found evidence that the data of Hogervorst are too low at high temperature for some systems [14], Prof. Aziz asked that we peg the heliumargon diffusion coefficient curve at high temperature.

Figure IV-12 is a full logarithmic plot of $\mathrm{D}_{12}$ as a function of temperature and helps point out part of the problem. The open circles represent the high temperature data $(300-1400 \mathrm{~K})$ of Hogervorst [23]. The open triangles are the only other data found in the literature above $500 \mathrm{~K}$ [24], while the closed triangles are considered to be the most accurate data available [20], but extend only up to $400 \mathrm{~K}$ [25]. The " $\mathrm{x}$ " on the plot is the solitary point determined in present study and is a value arrived at through a detailed study of several experiments. While it is not readily apparent on the logarithmic scale, the present data point is well over 108 higher than the curve

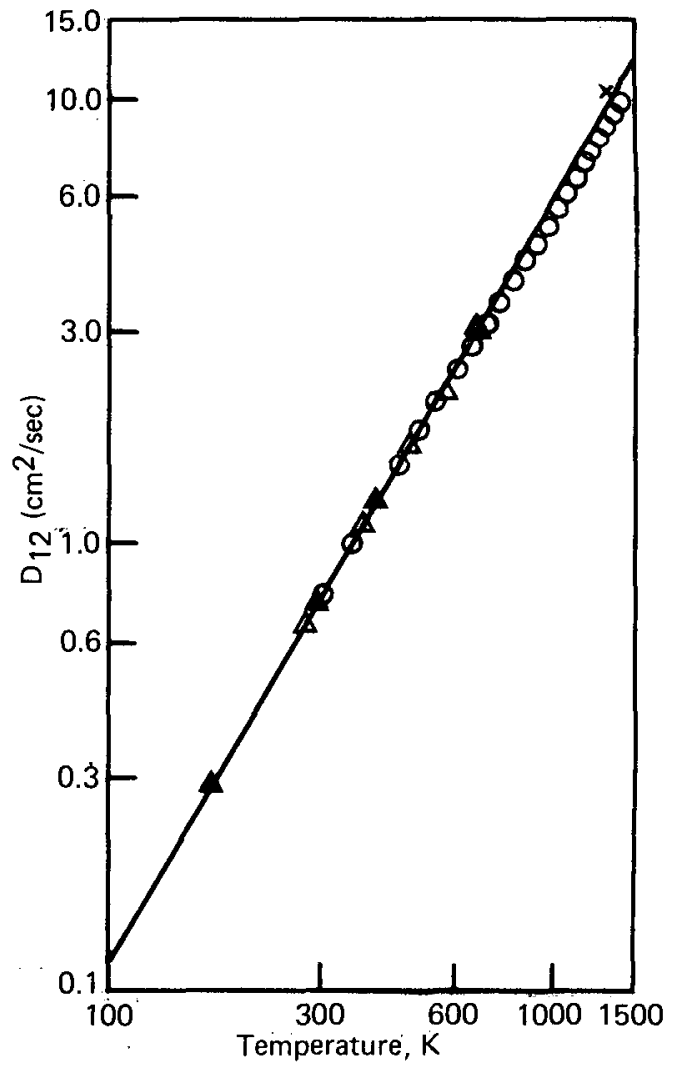

FIGURE IV-12 - Diffusion coefficient, $D_{12}$, as a function of temperature for $\mathrm{He}-\mathrm{Ar}$. The experimental points are: $x$, present work; O, Hogervorst (Ref. 23); $\triangle$, Suetin et al (Ref. 24); $\Delta$, van Heijningen et al (Ref. 25). The solid line represents a correlating function given by Equation 1 (Ref. 20). 
defined by Hogervorst's data. However, there are no other data in this temperature range to lend weight to either experimenter's work.

The line drawn through the data points in Figure IV-12 is a plot of the function

$$
\begin{aligned}
D_{12}= & \exp [-4.1886+1.552 \text { ln } \mathrm{T} \\
& -\ln \left(\ln \frac{4.10 \times 10^{7}}{\mathrm{~T}}\right)^{2} \\
& -1.71 / \mathrm{T}] .
\end{aligned}
$$

This equation is due to Marrero and Mason [20] and refers to equimolar compositions at atmospheric pressure. The theoretical basis of the correlation is the contribution of various parts of the intermolecular potential to the diffusion coefficient. However, for the temperatures of interest in this study, Equation 1 is an interpolation among experimental diffusion data below $500 \mathrm{~K}$ and molecular beam data above $1000 \mathrm{~K}$. The quoted uncertainties are \pm 58 at temperatures around $1000 \mathrm{~K}$.

Table IV-13 shows a comparison of Equation 1 with the present experimental data and that of Hogervorst at $1300 \mathrm{~K}$. It can be seen in tabular form, but is not so apparent on the logarithmic plot, that Hogervorst's data fall outside the listed error limits of Equation 1, while the present work is well within. Figure IV12 shows that the lower temperature data of Hogervorst $(<700 \mathrm{~K})$ and the data of the others are adequately predicted by Equation 1 .

Finally, we note that Arora et al [26] were not able to reproduce Hogervorst's diffusion data above $700 \mathrm{~K}$ to within the quoted $1.5 \%$ uncertainty for the system heliumargon. The authors used interatomic potentials derived from their own diffusion data taken over a temperature range of 275 to $323 \mathrm{~K}$ to extrapolate $\mathrm{D}_{12}$ values to $1400 \mathrm{~K}$. We have not yet had the opportunity to calculate collision integrals and verify this, or to compare predictions with our own data. Thus, the conclusion is that, based on the present experimental work plus indirect indications (interpolations and extrapolations), the data of Hogervorst are too low at high temperatures

\begin{tabular}{|c|c|c|c|c|}
\hline & $\begin{array}{c}\text { Temperature } \\
(\mathrm{K})\end{array}$ & $\begin{array}{l}\left(\mathrm{D}_{12}\right) \mathrm{exp} \\
\left(\mathrm{cm}^{2} / \mathrm{sec}\right) \\
\end{array}$ & $\begin{array}{l}\left(\mathrm{D}_{12}\right) \mathrm{calc} \\
\left(\mathrm{cm}^{2} / \mathrm{sec}\right) \\
\end{array}$ & \& dev \\
\hline $\begin{array}{l}\text { Present } \\
\text { work }\end{array}$ & 1307.4 & 10.049 & 9.729 & 3.29 \\
\hline $\begin{array}{l}\text { Hogervorst } \\
\text { (Ref. 23) }\end{array}$ & 1300 & 8.74 & 9.633 & -9.27 \\
\hline
\end{tabular}
$(\geq 700 \mathrm{~K})$.

\section{Table IV-13 - COMPARISON OF EXPERIMENTAL DIFFUSION COEFFICIENTS WITH EQUATION 1}




\section{Lithium chemical exchange with cryptands}

B. E. Jepson and G. C. Shockey

It is a general rule in chemical exchange that the greater the bonding difference between two species of an element, the greater the isotope effects at equilibrium [27]. The isotope exchange of lithium ions in a two-phase system utilizing an aqueous phase and an organic phase of macrocyclic ligands is represented by the following reaction:

$$
\begin{aligned}
& { }_{\mathrm{Li}\left(\mathrm{OH}_{2}\right) \mathrm{x}^{+}(\mathrm{aq})+{ }^{7} \mathrm{LiL}\left(\mathrm{OH}_{2}\right){ }_{y} \operatorname{TFA}(\mathrm{org})}= \\
& { }^{7} \mathrm{Li}\left(\mathrm{OH}_{2}\right) \mathrm{x}^{+}(\mathrm{aq})+{ }^{6} \mathrm{LiL}\left(\mathrm{OH}_{2}\right) \mathrm{y} \text { TFA (org) }
\end{aligned}
$$

where $\mathrm{L}=$ ligand

and $T F A=$ trifluoroacetate.

In the context of the above general rule, the hydration numbers, subscripts $x$ and $y$ in Reaction 1, are of interest. In the aquo complex, four water molecules form the inner hydration sphere with an indeterminate number of molecules less strongly bound in the outer hydration sphere $[28,29]$. Macrocyclic ligands offer a means to reduce the hydration number, $y$, in the organic phase complex.
The ligands examined in this report are (221) cryptand and (211) cryptand, the structures of which are shown in Figure IV-13. The lithium ion is bonded within the cavity of these structures by iondipole, ion-ion, and short range repulsive forces. Single-stage separation factors for (221) in the range of 1.035 have been found $[30,31]$. It is desirable from the aspect of maximizing the bonding differences that the hydration water in the lithium cryptate be at a minimum.

HYDRATION OF LITHIUM CRYPTATE

The preparation of the lithium cryptate solutions involved equilibrating a $2 \mathrm{M}$ aqueous solution of LiTFA with $0.15 \mathrm{M}$ and $0.14 \mathrm{M}$ chloroform solutions of (221) cryptand and (211) cryptand, respectively. The lithium concentration in the organic phase after equilibration was found to be $0.08 \mathrm{M}$ for both cryptands. A blank organic phase (no ligand present) was prepared by contacting $2 \underline{M}$ LiTFA with chloroform. The chloroform used in all cases contained $0.75 \%$ ethyl alcohol. LiTFA solubility in $\mathrm{CHCL}_{3}$ was previously found to be $0.0003 \mathrm{M}$ and can be considered negligible in this work. Fifteen Karl Fischer titrations yielded water concentrations as follows:

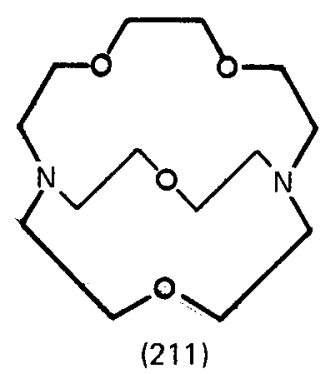

FIGURE IV-13 - cryptand structures. 
blank, $0.07 \pm 0.01$ (SD) $\mathrm{M}$;

(211), $0.07 \pm 0.01$ (SD) $\mathrm{M}$;

and $(221), 0.13_{5} \pm 0.01$ (SD) $\mathrm{M}$.

If it is assumed that the water in excess of that in the blank is present as hydration water of the lithium cryptate, values can be assigned to the subscript $y$ in $R e-$ action 1. For (211) exchange, $y=0.0 \pm$ 0.2 ; and for (221) exchange, $y=0.8 \pm 0.2$. An inspection of space filling CPK (CoreyPauling-Koltun) molecular models of the lithium cryptates illustrates why the cryptands are capable of excluding most or all hydration water. The cavity sizes, $1.1 \AA$ radius for 221 and $0.8 \AA$ radius for 211, are much too small to accommodate a water molecule [32]. The water oxygen ligand atom must closely approach the oxa ligands of the cryptand if it is to attain close proximity to the complexed lithium cation. Also the lithium cryptate must exist as an ion pair with the TFA ${ }^{-}$anion.

\section{EXCHANGE RATE KINETICS WITH 2 II CRYPTAND}

Details of the procedure for evaluating the heterogeneous exchange rate kinetics have been previously described [30]. In general, it involves contacting two phases with different isotopic compositions and following the change in isotopic compositions as a function of time. The results for 211 kinetics are shown in Table IV-14 along with a parallel study of 221 kinetics. The concentrations, phase volume ratios, and mixing techniques for the two studies were as close to identical as possible. Exchange with 221 was essentially complete within $0.5 \mathrm{~min}$; however, some resistance to exchange was noted with 211 exchange. Since conditions for mass transfer in both systems were very similar, a reaction rate limitation is suggested. A plot of - log (1-F) as a function of time ( $F=$ fraction exchanged) in the range of $58 \%$ to $94 \%$ exchange completion yields a rate constant of $k=0.2 \mathrm{~min}^{-1}$ corresponding to a halftime of $3.5 \mathrm{~min}$. The more rapid exchange during the first fraction of a minute probably was the result of some net interfacial mass transport due to slight variations from equilibrium values in the starting lithium concentrations.

\section{CONCLUSIONS}

One molecule of water of hydration is present in the organic phase 221 cryptand complex of lithium trifluoroacetate while the 211 complex excludes all water of

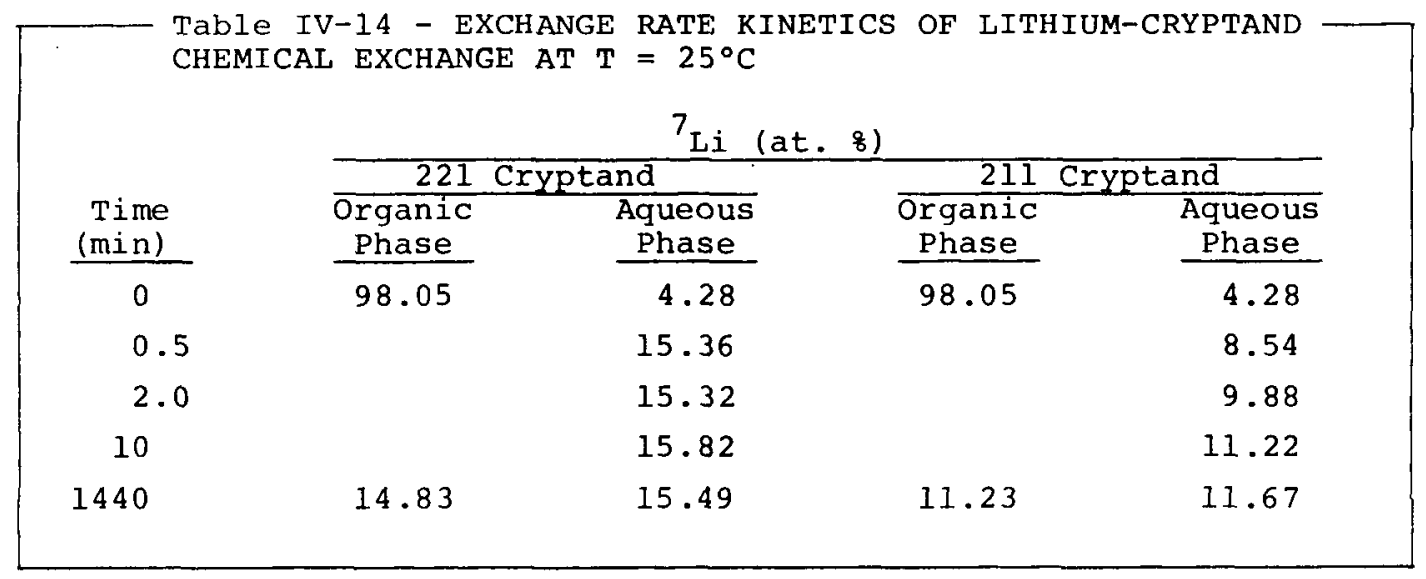


hydration. Since the last water is the most strongly bound, it is not surprising that the exchange rate of Reaction 1 is slow for exchange with 211 . The large stability constant of lithium cryptate supports the reaction rate limitation. The stability constant of $\mathrm{Li}(211)^{+}$in water is $\log \mathrm{K}_{\mathrm{S}}=5.5$ while that of $\mathrm{Li}(211)^{+}$is $\log \mathrm{K}_{\mathrm{s}}=2.5$, a $\mathrm{K}_{\mathrm{s}}$ difference of three orders of magnitude [32].

\section{Calculations in}

\section{plutonium chemistry}

\section{Short algorithms for plutonium chemistry problems}

G. L. Silver

Recently, a number of books on optimization have appeared $[1,2]$, and while some of them describe the sequential simplex algorithm, none of them makes the observation that this algorithm can be shortened to the point that it becomes a powerful tool for computing equipment as simple as the programmable pocket calculator. It has recently been shown, however, that the algorithm can be abbreviated by retaining but one of the traditional operations $\left(C_{w}\right)$, and augmenting this operation by a new operation designated as "diminished expansion" [3].

Parkinson and Hutchinson have made an extensive study of the arithmetic operations in the traditional simplex algorithm, and have concluded that the numerical factors traditionally used in this routine may not be the best possible selection [4]. Since the abbreviated routine suggested here has fewer factors than the traditional simplex routine, it would appear that a similar study for the abbreviated routine would be both interesting and useful. In the absence of such a study, however, an expansion of about $25 \%$ beyond the reflection point may be appropriate.

Listed in Tables $\mathrm{V}-1$ and $\mathrm{V}-2$, respectively, are two- and three-variable minimization routines abbreviated as described above. These routines may be used to solve a variety of chemistry problems by the method of proportional equations [5]. The routines are suitable for the HP-67 or HP-97 calculators manufactured by the Hewlett Packard Company. The meaning of the symbols is described in Reference 3. For the routines 1 isted in Tables $\mathrm{V}-1$ and $\mathrm{V}-2$, matrices are useful mnemonics for data entry. For the two-variable routine, enter the data as follows:

$\begin{array}{ccc}\text { POINT } & \text { REGISTERS } & \begin{array}{c}\text { FUNCTION VALUE } \\ \text { REGISTER }\end{array} \\ \mathrm{X} 1, \mathrm{Y} 1 & 1,2 ; 5,6 & 7 \\ \mathrm{X} 2, \mathrm{Y} 2 & 3,4 ; 5,6 & 8 \\ \mathrm{X} 3, \mathrm{Y} 3 & 5,6 & 9\end{array}$

For the three-variable routine, enter the data as follows:

\begin{tabular}{|c|c|c|}
\hline POINT & - REGISTERS & $\begin{array}{l}\text { FUNCTION } \\
\text { VALUE } \\
\text { REGISTER }\end{array}$ \\
\hline $\mathrm{X} 1, \mathrm{Y} 1, \mathrm{Z} 1$ & $5,9,13 ; 8,12,16$ & 1 \\
\hline $\mathrm{X} 2, \mathrm{Y} 2, \mathrm{Z} 2$ & $6,10,14 ; 8,12,16$ & 2 \\
\hline $\mathrm{X} 3, \mathrm{Y} 3, \mathrm{Z} 3$ & $7,11,15 ; 8,12,16$ & 3 \\
\hline $\mathrm{X} 4, \mathrm{Y} 4, \mathrm{Z} 4$ & $8,12,16$ & 4 \\
\hline
\end{tabular}

After each point is entered, execute the objective function at Label 0 , and store its value at the appropriate register. Objective functions should be so written that trial values of $X$ and $Y$ are recalled from registers 5 and 6 , respectively, in the two-variable minimization routine, and 


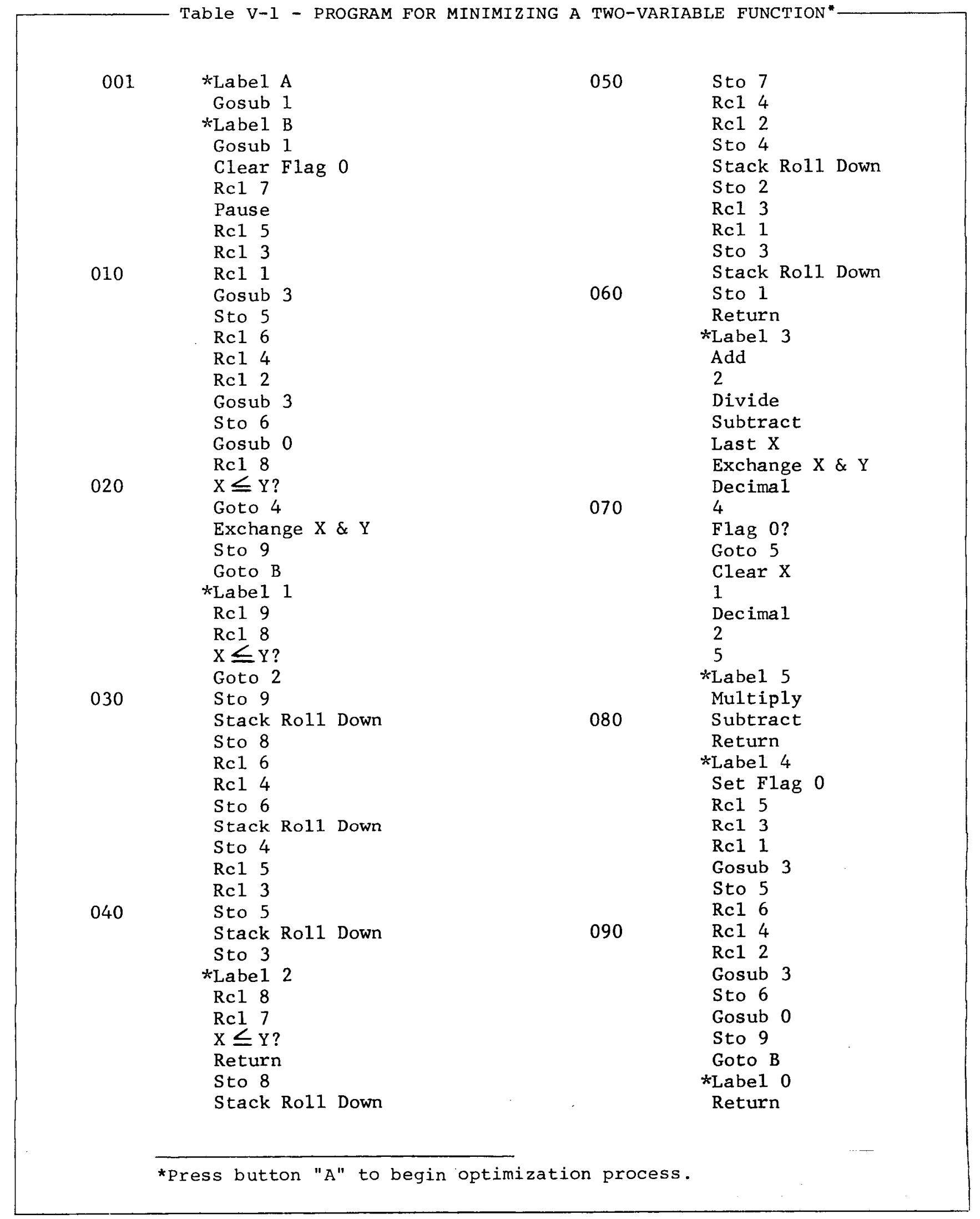




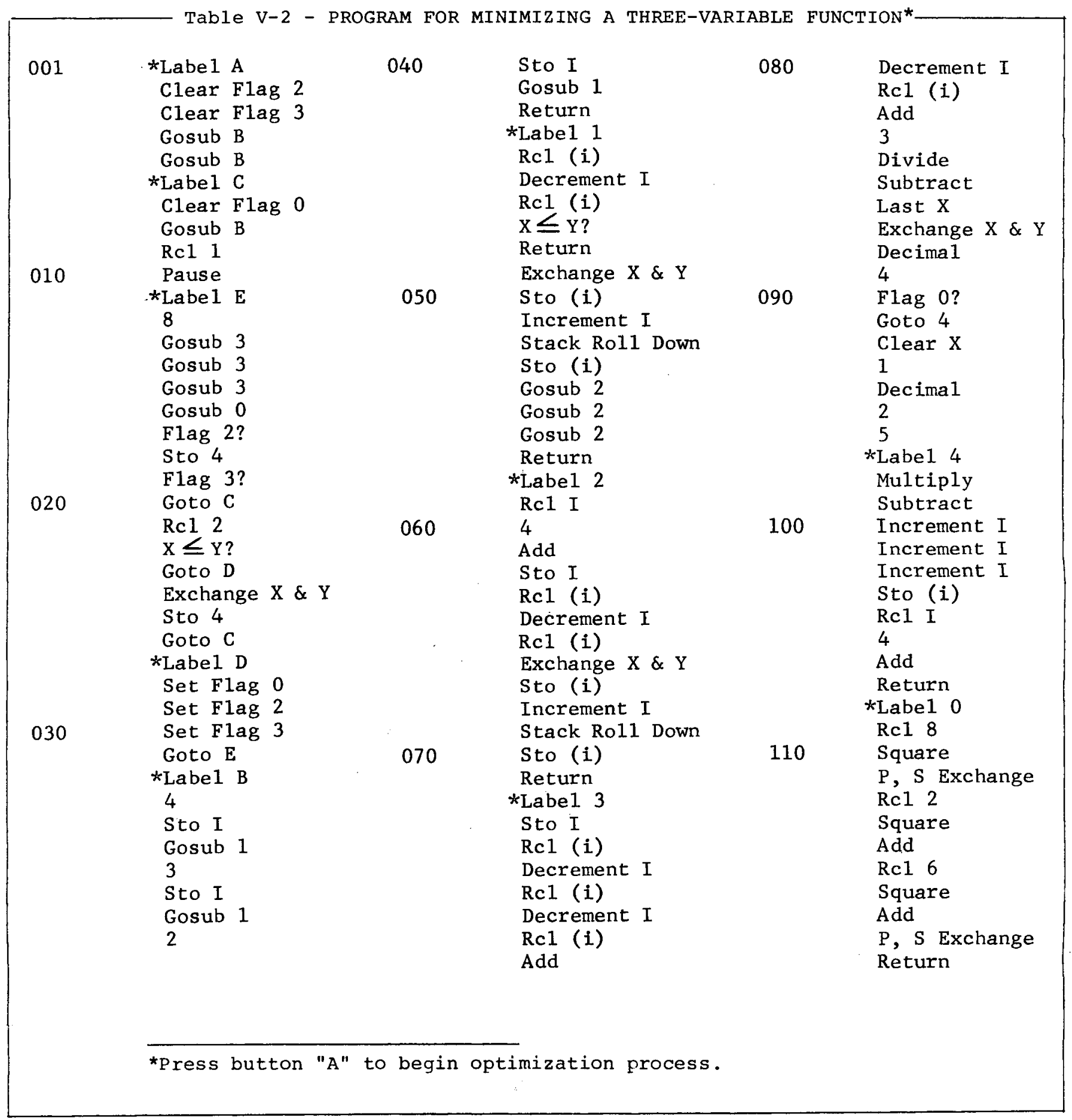


from registers 8,12 , and 16 in the threevariable minimization routine. (The three-variable routine shown in Table $\mathrm{V}-2$ includes the test function $\mathrm{X}^{2}+\mathrm{Y}^{2}+\mathrm{z}^{2}$ at Label zero to illustrate this recall. "P, S Exchange" signifies interchange of the primary and secondary storage registers.) For the two-variable routine, registers $A, B, C, D, E, I, 0$, and all secondary storage registers are unused, whereas for the three-variable routine, only registers $0,17,18,19, \mathrm{~A}, \mathrm{~B}, \mathrm{C}, \mathrm{D}$, $E$ are unused. (Flag 0 is a command cleared flag, whereas flags 2 and 3 are test cleared flags. Changing the numerical factors in the operations of diminished expansion (E) and contraction $\left(\mathrm{C}_{\mathrm{w}}\right)$ provides a tactic for dealing with the problem of false convergence.) In the two-variable routine, the best (minimum) value of $f(X, Y)$ is stored at register 7 , and the corresponding values of $X$ and $Y$ are stored at registers 1 and 2 , respectively. For the three-variable routine, the best (minimum) value of $f(X, Y, Z$ ) is found at register 1 , and the corresponding values of $\mathrm{X}, \mathrm{Y}$, and $\mathrm{Z}$ at registers 5,9 , and 13 , respectively.

Charles Wohl of the Particle Data Group, Lawrence Berkeley Laboratory, has prepared a two-variable, abbreviated, sequential simplex routine which requires less than 80 steps [6]. While shorter than the routine given in Table $\mathrm{V}-\mathrm{l}$, it does not appear to execute as quickly as that routine. It was wohl who suggested that the point of diminished expansion (E) and the contraction point $\left(\mathrm{C}_{w}\right)$ be calculated from the same subroutine, a most valuable suggestion for the preparation of short optimization routines. Using this procedure, the numerical factor for the expansion operation in Tables $\mathrm{V}-1$ and $\mathrm{V}-2$ has been taken as 1.25 , and the numerical factor for the contraction operation as 0.4. As remarked above, other values for these factors may be selected, provided the value of the former exceeds unity, and the value of their product is one half. For example, $10 / 9$ and 0.45 is a satisfactory choice, and these numbers may be a better selection for three-, and higher, dimensional simplex routines. Readers skilled in the art of programming can probably further shorten and simplify the contents of Tables $\mathrm{V}-1$ and $\mathrm{V}-2$, as the process of making improvements in computer programs seems to be an interminable one.

\section{Program for plutonium valences in environmental water}

G. L. Silver

It does not seem to be generally recognized that the equilibrium distribution of plutonium species in water of the natural environment can be estimated if some of the properties of the water are known. The properties of natural water which make possible such estimations are: $\mathrm{pH}$, redox potential, and alpha coefficients (sometimes called "alpha factors") for the four oxidation states of the plutonium. In principle at least, all of these parameters are subject to experimental determination. Listed in Table $\mathrm{V}-3$ is a program prepared for the Hewlett Packard Co. models HP-67 or HP-97 calculators; this program rapidly performs oxidation state distribution calculations for plutonium (or uranium, neptunium, and americium -- neglecting the uncommon, divalent state of this last element, however).

To use this program, it is necessary to know the numerical value of several 


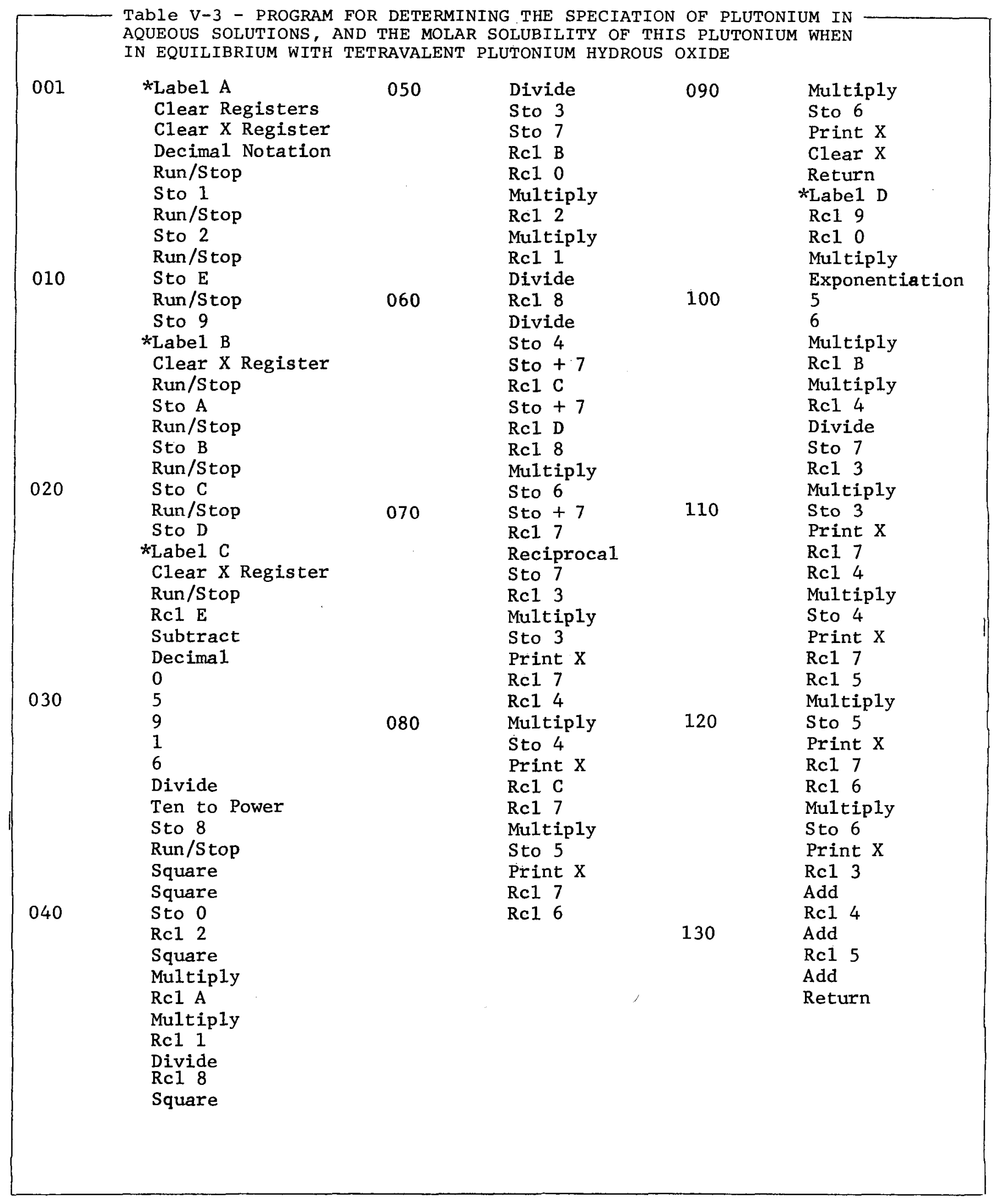


parameters of importance in plutonium chemistry. It is necessary to know the numerical value of $\mathrm{Kl}$, the equilibrium constant for reaction 1 :

$$
\begin{aligned}
2 \mathrm{Pu}^{4+}+2 \mathrm{HOH} & =\mathrm{Pu}^{3+}+\mathrm{PuO}_{2}^{+}+4 \mathrm{H}^{+} \\
\mathrm{K} & =\mathrm{Kl}
\end{aligned}
$$

as well as the numerical value of $K 2$, the equilibrium constant for reaction 2 :

$$
\mathrm{Pu}^{4+}+\mathrm{PuO}_{2}^{+}=\underset{\mathrm{K}=\mathrm{K} 2}{\mathrm{Pu}}{ }^{3+}+\mathrm{PuO}_{2}^{2+}
$$

To begin the program, press button "A". Then, during the periods of pause, enter the necessary numbers in the following order (numerical values in parentheses indicate typical numerical values which have been used in the past):

1. $\mathrm{K} 1(6.97 \mathrm{E}-04)$

2. K2 (13.2)

3. Standard potential of $\mathrm{Pu}(\mathrm{VI}) / \mathrm{Pu}(\mathrm{V})$ couple, volts $(0.9164)$

4. Solubility product of tetravalent plutonium hydrous oxide (IE-56) ----Location of "B"-----

5. Alpha coefficient for $\mathrm{Pu}$ (III) (AW)

6. Alpha coefficient for Pu(IV) (AX)

7. Alpha coefficient for $P u(V)$

8. Alpha coefficient for $\mathrm{Pu}(\mathrm{VI})$ ----Location of "C"-----

9. Measured redox potential of environmental water, volts

10. Measured acidity of natural water, molar

The program then calculates and displays the following oxidation state proportions: Pu(III) first (stored at register 3); $\mathrm{Pu}$ (IV) second (stored at register 4); and
Pu(VI) last (stored at register 6). The program may be restarted at locations "B" and "C" by pressing buttons "B" and " $\mathrm{C}$ ", respectively. Press button " $D$ " to calculate the absolute molar solubilities of the oxidation states in equilibrium with hydrous tetravalent plutonium oxide. The last number then displayed in the working (X) register is the total equilibrium solubility of the plutonium in the system with properties defined by the user.

Solved examples which may be used to test the program for satisfactory operation are given below:

A. $E=+0.96$ volt $, \mathrm{H}^{+}=0.34 \underline{\mathrm{M}}, \mathrm{AW}=5.6$, $\mathrm{AX}=9.1, \mathrm{AY}=1, \mathrm{AZ}=1.1 \quad[7]$

B. $E=0.99915$ volt, $\mathrm{H}^{+}=0.598437 \underline{\mathrm{M}}$, no complexation of $\mathrm{Pu}$ ions (all alpha coefficients are therefore taken as unity) [8]

C. $E=0.99951$ volt, $H=0.604668 \mathrm{M}$, $\mathrm{AW}=\mathrm{AY}=\mathrm{AZ}=1, \mathrm{AX}=1.0496$ [8]

D. $E=0.9437$ volt, $H=0.1 \underline{M}$, $\mathrm{K} 1=6.56 \mathrm{E}-04, \mathrm{~K} 2=12.8, \mathrm{AW}=63.08$, $\mathrm{AX}=279.6, \mathrm{AY}=189.0, \mathrm{AZ}=65.45$

[9]

The Run/Stop command causes the calculator to stop and await input from the user, who, after having entered the desired numerical data, again presses the Run/stop button. "Ten to power" implies ten raised to the number given in the working register, and 0.05916 is the Nernst Equation factor for $25^{\circ} \mathrm{C}$. "Decimal notation" instructs the calculator on the format for output (this step may be deleted); "Sto + 7" means that a number is added to the contents of register 7; "Exponential" followed by 56 means that the equilibrium constant for the reaction

$$
\mathrm{H}^{+}+\mathrm{OH}^{-}=\mathrm{HOH} \quad \mathrm{K}_{\mathrm{W}}=10^{14}
$$

has been raised to the fourth power. 
Alpha coefficients for plutonium (or uranium, neptunium, and americium) ions may be subject to direct determination by a process such as measurement of the increased solubility of a sparingly soluble compound in natural water. Such techniques have not yet been given adequate consideration, however, to allow a judicious appraisal of their merit $[10,11]$. Regions of predominance of oxidation states as calculated with the program can, at least in the case of no complexation of the various ions, be checked by consulting a potential-pH diagram for plutonium [12]. Examples illustrating application of the program have been discussed in many references $[13,14,15,16]$. There are more complicated methods for computing plutonium valence state distributions, but the advantages of such methods are questionable [17].
Because the constants $K 1$ and $K 2$ involve ions with charges as high as +4 , the numerical values of these constants may be quite sensitive to the ionic strength of the medium in which the environmental plutonium occurs, and the values of these constants may be quite different for saline solutions, such as occur in the sea, and for fresh water from unpolluted brooks and ponds [18]. There are no completely satisfactory computational methods for adjusting the values of equilibrium constants from a medium in which they have been measured to some other, dissimilar medium. This has been repeatedly emphasized in many places; a particularly colorful example is the discourse provided by La Mer, who pointedly remarks that the activity coefficient of the calcium ion is not the same in solutions of calcium chloride and sodium chloride, even when the ionic strengths of the two solutions are identical [19]. 


\section{References}

\section{Low temperature research}

1. E. A. Mason and W. E. Rice, J. Chem. Phys., 22, 522 (1954).

2. J. M. Farrar and Y. T. Lee, J. Chem. Phys., 57, 5429 (1972).

3. R. Ahlrichs, R. Penco, and G. Scoles, Chem. Phys., 19, 119 (1977).

4. W. Baver, B. Lantzsch, J. P. Toennies, and K. Walaschewski, Chem. Phys., 17, $19(1976)$.

5. I. F. Silvera and V. V. Goldman, J. Chem. Phys., 69, 4209 (1978).

6. A. R. W. McKellar and H. L. Welsh, Can. J. Phys., 52, 1082 (1974).

7. R. G. Gordon and J. K. Cashion, J. Chem. Phys., 44, 1190 (1966).

8. A. A. Evett and H. Margenau, Phys. Rev., 99, 1021 (1953).

9. W. Meyer (unpublished).

10. W. Meyer, Chem. Phys., 17, 27 (1976).

11. W. R. Wilkes, Commission I Meeting of the International Institute of Refrigeration, Tokyo, Japan, 67 (1970).

12. W. A. Wakeham, J. Phys. E: Sci. Inst., 4, 433 (1971).

\section{Separation chemistry}

1. P. L. Keister, P. E. Figgins, and R. M. Watrous, Recovery and Purification of Uranium-234 from Aged
Plutonium-238, MLM-2490 (January 20, 1978), $17 \mathrm{pp}$.

\section{Separation research}

1. Mound Facility Activities in Chemical and Physical Research, JanuaryJune 1979, MLM-2654 (October 29, 1979), p. 12 .

2. W. M. Rutherford, J. Chem. Phys., 59, 6061 (1979).

3. Mound Facility Activities in Chemical and Physical Research, JanuaryJune 1979, MLM-2654 (October 29, 1979), p. 18 .

4. G. Panson, USAEC Report NYO-6239 (Section 6), 1953.

5. H. Korsching and K. Wirtz, Naturwissenschaften 27,367 (1939).

6. Mound Facility Activities in Chemical and Physical Research, JanuaryJune 1979, MLM-2654 (October 29, 1979), p. 25 .

7. K. Berkling, R. Helbing, K. Kramer, H. Pauly, C. Schlier, and P. Toschek, Effective Collision Cross Section in Scattering Experiments, MLM-1841(TR) (August 20, 1971), 23 pp. [translated by $W$. L. Taylor from zeitschrift für Physik, 166, 406-428 (1962)].

8. J. L. Shinn, Velocity-Dependence of the Total Elastic Scattering Cross Section for Neon-Neon and Neon-Argon Collisions, University of Virginia (PhD Thesis), 1973.

9. R. J. Munn, E. A. Mason, and F. J. Smith, J. Chem. Phys., 41, 3978 (1964). 
10. W. Hogervorst, Physica, 51, 90 (1971).

11. E. A. Mason and W. E. Rice, J. Chem. Phys., 22, (1954).

12. C. Y. Ng, Y. T. Lee, and J. A. Barker, J. Chem. Phys., 61, 1996 (1974).

13. H. M. Lin and R. L. Robinson, Jr., J. Chem. Phys., 54, 52 (1970).

14. David Cain and W. L. Taylor, J. Chem. Phys., 71, 3601 (1979).

15. G. A. DuBro and S. Weissman, Phys. Fluids, 13, 2682 (1970).

16. S. Weissman and G. A. DuBro, Proc. Fifth Sym. Thermophysical Prop.' Am. Soc. Mech. Eng., N.Y. (1970).

17. S. Weissman, Phys. Fluids, 17, 254 (1974).

18. S. Weissman, Phys. Fluids, 16, 1425 (1973).

19. S. Weissman and G. A. DuBro, Phys. Fluids, 13, 2689 (1970).

20. T. R. Marrero and E. A. Mason, J. Phys. Chem. Ref. Data, I, 1 (1972).

21. R. A. Aziz, private communication to the authors.

22. R. A. Aziz, P. W. Riley, U. Buck, G. Maneke, J. Schleusener, G. Scoles, and U. Valbusa, J. Chem. Phys., 71, 2637 (1979).

23. W. Hogervorst, Physica, 51, 59 (1971).
24. P. E. Suetin, B. A. Kalinin, and A. E. Loiko, Sov. Phys. - Tech. Phys.' 15, 1349 (1971); B. A. Ivakin, A. E. Loiko, and P. E. Suetin, op cit, 22, 522 (1977); B. A. Kalinin and P. E. Suetin, Heat Transfer - Sov. Res., 7. 146 (1975).

25. R. J. J. van Heijningen, J. P. Harpe, and J. J. M. Beenakker, Physica, 38, 1 (1968).

26. P. S. Arora, H. L. Robjohns, and P. J. Dunlop, Physica, 95A, 561 (1979).

27. J. Bigeleisen and M. G. Mayer, "Ca1culation of Equilibrium Constants for Isotope Exchange Reactions," J. Chem. Phys., 13:5, 261-267 (1947).

28. J. O'M. Brockris, P. P. S. Saluja, and G. Madan, The Study of Ionic Solvation, Research and Development Progress Report No. 569, U. S. Department of the Interior, June 1970 .

29. E. Gluekauf, "The Influence of Ionic Hydration on Activity Coefficients in. Concentrated Electrolyte Solutions," Trans. Faraday Soc., 51, 1235-1244 (1955).

30. B. E. Jepson and G. A. Cairns, Lithium Isotope Effects in Chemical Exchange with (221) cryptand, MLM-2622 (June 8, 1979).

31. Mound Facility Activities in Chemical and Physical Research: January-June 1979, MLM-2654 (October 29, 1979), pp. 30-35. 
32. R. M. Izatt and J. J. Christensen, Progress in Macrocyclic Chemistry, Volume 1, John Wiley \& Sons, New York, 1979, p. 131.

\section{Calculations in plutonium chemistry}

1. P. R. Adby and M. A. H. Dempster, Introduction to Optimization Methods, Halsted Press, New York, 1974.

2. G. R. Walsh, Methods of Optimization, John Wiley \& Sons, New York, 1975.

3. G. L. Silver, Optimization Algorithm, MLM-2638 (August 24, 1979), 11 pp.

4. J. M. Parkinson and D. Hutchinson in Numerical Methods for Non-linear Optimization, F. A. Lootsma (ed.), Academic Press, New York, 1972, p. 115 .

5. G. L. Silver, Radiochem. Radioanal. Lett., $27(4), 243$ (1976):

6. Charles Wohl, Particle Data Group, Lawrence Berkeley Laboratory, University of California, Berkeley, California 94720, private communication.

7. G. L. Silver, Radiochem. Radioanal. Lett., 9(5-6), 315 (1972).

8. G. L. Silver, Radiochimica Acta, 21, 54 (1974).

9. G. L. Silver, J. Inorg. Nucl. Chem. 34, 1857 (1972).
10. G. L. Silver, Plutonium in Natural Waters, MLM-1870 (December 16, 1971), $15 \mathrm{pp}$.

11. G. L. Silver, Agueous Plutonium Chemistry: Some Minor Problems, MLM-1871 (May 26, 1972), 68 pp. (See p. 67.)

12. G. L. Silver, Radiochem. Radioanal. Lett., $7(1), 1$ (1971).

13. G. L. Silver in Mound Facility Activities in Chemical and Physical Research: July-December 1977, MLM-2506 (May 1, 1978), p. 18 .

14. G. L. Silver in Mound Laboratory Activities in Chemical and Physical Research: January-June 1977, MLM-2450 (October 4, 1977), p. 33 .

15. G. L. Silver in Mound Laboratory Activities for the Division of Physical Research: January-June 1976, MLM-2354 (September 30, 1976), p. 26.

16. G. L. Silver, Optimization and Plutonium Equilibrium, MLM-2373 (October $15,1976), 19$ pp. (See Index.)

17. G. Naegele, Zur Loeslichkeit von Plutonium in Wasser, KFK-2404 (December 1977), $129 \mathrm{pP}$.

18. A. Ringbom, Complexation in Analytical Chemistry, Interscience Publishers, New York, 1963, p. 23.

19. V. K. La Mer, J. Phys. Chem., 66, 973 (1962). 


\title{
Distribution
}

\author{
EXTERNAL
}

TID-4500, UC-4 and UC-22 (194)

Technical Report Library, Monsanto, St. Louis

H. N Hill, DOE/Dayton Area Office

R. B. Craner, Sandia Laboratories Albuquerque

D. Emin, Sandia Laboratories Albuquerque

B. Morosin, Sandia Laboratories Albuquerque

P. M. Richards, Sandia Laboratories Albuquerque

A. C. Switendick, Sandia Laboratories Albuquerque

E. L. Venturini, Sandia Laboratories Albuquerque

R. K. Flitcraft, Monsanto Research Corporation

W. J. Haubach, DOE/Division of Basic Energy Sciences

N. Haberman, DOE/Division of Nuclear Research and Application

W. H. Weyzen, DOE/Office of Health and Environmental Research

F. D. Stevenson, DOE/Division of Basic Energy Sciences

C. P. Sutter/R. N. Diebel, Atlantic Richfield

D. White, University of Pennsylvania

R. N. Zare, Columbia University

\section{INTERNAL}

W. R. Amos

D. Cain

W. T. Cave

W. R. Deal

P. E. Figgins

M. R. Hertz

C. W. Huntington

B. E. Jepson

P. L. Keister

$\mathrm{K}$. W. Laughlin

$\mathrm{J}$. R. McClain

G. T. McConvilie

W. J. Roos

G. C. Shockey

G. L. Silver

G. E. Stuber

W. M. Rutherford

W. L. Taylor

R. E. Vallee

K. D. Westrick

R. W. York

Document Control

Library (15)

Publications

Published by Information Services:

Patricia A. Fitzharris, Editor 